\author{
UNIVERSIDADE DE SÃO PAULO \\ FACULDADE DE ODONTOLOGIA DE BAURU
}

CAMILA MOREIRA MACHADO

\begin{abstract}
Análise do efeito de adição do marcador Rodamina B em propriedades mecânicas de sistemas adesivos não simplificados
\end{abstract}





\section{Análise do efeito de adição do marcador Rodamina B em propriedades mecânicas de sistemas adesivos não simplificados}

Dissertação apresentada à Faculdade de Odontologia de Bauru da Universidade de São Paulo para obtenção do título de Mestre em Ciências no Programa de Ciências Odontológicas Aplicadas, na área de concentração Dentística.

Orientadora: Profa. Dra. Linda Wang

Versão corrigida 


\begin{tabular}{|l}
\hline Machado, Camila Moreira \\
Análise do efeito de adição do marcador Rodamina B \\
em propriedades mecânicas de sistemas adesivos não \\
simplificados / Camila Moreira Machado. - Bauru, 2014. \\
91 p. : 1. ; 31cm. \\
Dissertação (Mestrado) - Faculdade de Odontologia \\
de Bauru. Universidade de São Paulo \\
Orientadora: Profa. Dra. Linda Wang \\
\end{tabular}

Nota: A versão original desta dissertação encontra-se disponível no Serviço de Biblioteca e Documentação da Faculdade de Odontologia de Bauru - FOB/USP.

Autorizo, exclusivamente para fins acadêmicos e científicos, a reprodução total ou parcial desta dissertação/tese, por processos fotocopiadores e outros meios eletrônicos.

Assinatura:

Data:

Comitê de Ética da FOB-USP

CAAE: 17406313.6 .0000 .5417

Data: $10 / 02 / 2014$ 


\title{
DEDICATÓRIA
}

Dedico este trabalho especialmente às pessoas que sonharam junto comigo e não mediram esforços para me ajudar a realizar este sonho...

\begin{abstract}
A Deus,
Pela constante presença em minha vida, por compreender os meus anseios e renovar, a cada manhã, a minha força e a minha coragem para alcançar meus objetivos. Sem ti, meu pai, tudo em minha vida seria em vão. Muito obrigada por sempre guiar os meus passos.
\end{abstract}

\section{Aos meus amados pais Urivando e Everli,}

Pelo exemplo de vida que sempre foram para mim. Por deixarem eu seguir o meu caminho em busca da conquista dos meus sonhos, mesmo sabendo que o maior sacrificio seria a distância entre nós. Por se fazerem presentes na minha vida em todos os momentos, apesar da distância física. Por serem meus maiores incentivadores e terem sempre acreditado em mim.Vocês são os maiores responsáveis por eu ter cumprido mais esta etapa. Serei eternamente grata a vocês por tudo que fizeram e fazem por mim. Amo

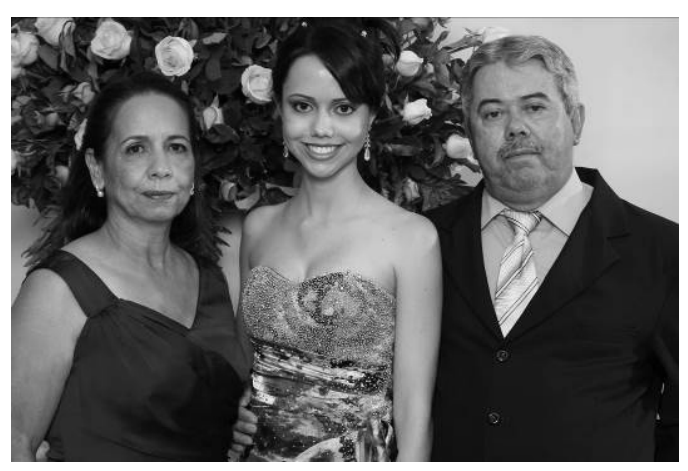
muito vocês! 



\section{À minha irmã Renata,}

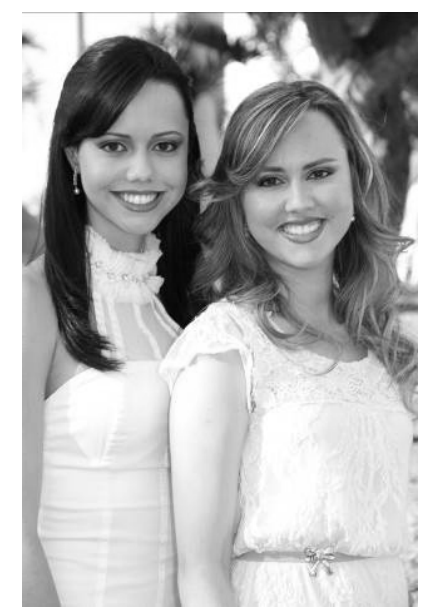

Por ser o meu maior referencial de determinação, força, coragem, humildade, paciência e compaixão. Por estar presente em todos os momentos da minha vida. Por saber que você estará ao meu lado sempre que eu precisar. Somos tão diferentes e ao mesmo tempo tão iguais. Eternamente será a minha "Tata". Amo você incondicionalmente!

\section{Às minhas amigas-irmãs Adriana, Marina e Martha}

Vocês são presentes de Deus na minha vida. No início da nossa caminhada éramos um quarteto. Deus nos presenteou com o presente mais grandioso de todos: o nascimento da princesa Ana Luísa. E assim, o quinteto estava formado. Marina, você é uma pessoa indescritível, um anjo que Deus colocou na terra para cuidar de todos que convivem com você. Adriana, você possui uma grandeza infinita e um coração enorme. Muito obrigada por estar sempre ao meu lado, me ajudando e me apoiando. Martha, nossa miss do quinteto! Tão linda por fora e com uma beleza indescritivel por dentro. Obrigada por ser quem você é. Meninas, muito obrigada por tudo. Existem irmãos que Deus nos permite escolher e amá-los infinitamente. Assim é o meu amor por vocês! Não poderia esquecer das nossas “cãopanheirinhas" Lola e Kika, que alegram

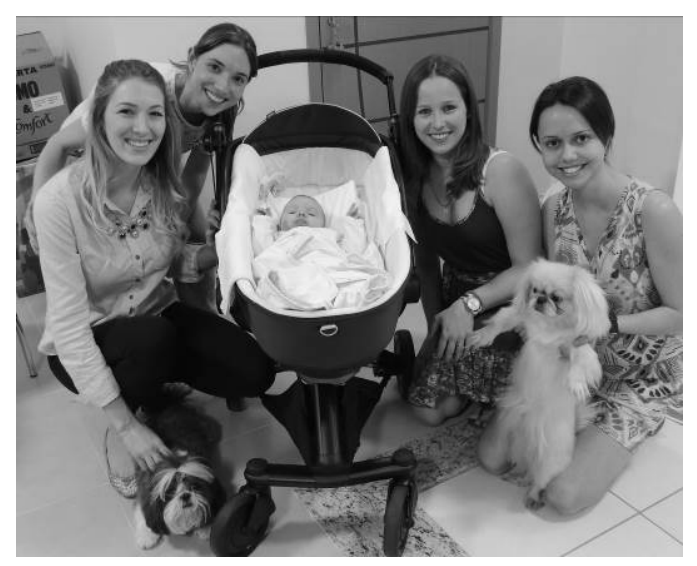
nossas vidas diariamente. 



\section{AGRADECIMENTOS}

Aos meus familiares, em especial à minha avó. Obrigada pela torcida e preocupação. Mesmo longe sentia seus cuidados.

Aos meus amigos de Goiás, Mayara, Priscilla e Paulo Vitor. É tão maravilhoso saber que a nossa amizade continua a mesma apesar de nos vermos poucas vezes ao ano. Obrigada pelo carinho e torcida. Amo vocês!

Às minhas amigas de Bauru, Mayara e Cassiana. Mayara, minha irmã na fé. Deus te colocou na minha vida no momento certo. Obrigada pelos conselhos, pelas conversas e por sempre me ajudar. Cassiana, você é uma pessoa muito especial, tem um enorme coração. Amo vocês!

Aos amigos de mestrado, Alfredo, Ana Paula, Fábio, Letícia, Lígia, Luara, Maria Angélica, Marlyni, Melody e Thamires. Obrigada pela agradável convivência, conhecimentos compartilhados, momentos nas clínicas, aulas e seminários. Vocês são especiais!

Ao Odair, obrigada por toda a ajuda nesta pesquisa. Pela paciência de me ensinar o método, desde a dissolução da rodamina $\mathrm{B}$ até os testes de microtração. Obrigada por ter sido tão acessível, independente do horário, para atender meus telefonemas e esclarecer minhas dúvidas. Sem a sua ajuda, esta pesquisa teria se tornado mais difícil. 

Aos colegas de doutorado, em especial, a Kiki. Muito obrigada pela sua ajuda na metodologia da microdureza, pelas trocas de experiência, pela parceria e pelos momentos de conversa e descontração. Você também faz parte desta conquista!

À minha dupla de clínica, Elaine. Realmente, foi Deus quem te colocou na minha vida. Obrigada pela parceria nas clínicas de pós-graduação e seminários, pela paciência e pela alegria contagiante. Torço muito por ti!

Aos amigos de Bauru, Danna, Roger e Thales e aos jovens da Primeira Igreja Batista de Bauru. Muito obrigada pelo carinho e amizade de vocês. Vocês fazem meus dias mais felizes! Amo vocês!

À Leslie por ter me ensinado os primeiros passos de iniciação científica. Muito obrigada pela paciência, pelos ensinamentos, pelas conversas e pelos momentos de descontração.

Às alunas de iniciação científica, Rafaela e Mariana, por participarem da minha construção profissional.

Aos alunos da graduação, obrigada pela amizade e pela confiança e por participarem da minha construção profissional. Agradeço, especialmente, aos alunos da Turma LII, com os quais pude conviver intensamente durante um ano e meio e criei laços afetivos que levarei para sempre. Vocês são muito especiais!

Aos membros da banca examinadora. Obrigada por aceitarem o convite e por contribuírem da melhor forma possível para este trabalho. 

Aos professores do departamento de Dentística, Endodontia e Materiais Odontológicos. Vocês contribuíram imensamente para o meu crescimento. Agradeço, especialmente, ao Prof. Dr. Eduardo Batista Franco por ter sido o grande referencial de professor e profissional durante a minha graduação. Obrigada por todos os ensinamentos transmitidos.

Aos funcionários do departamento de Dentística, Endodontia e Materiais Odontológicos, especialmente, Audria, Natália, Nelson, Charlene, Rita, Elísio, Zuleica, Sandrinha e Alcides. Obrigada por toda a ajuda.

Aos professores e funcionários do departamento de Ciências Biológicas, em especial à Prof ${ }^{\mathrm{a}}$. Dr ${ }^{\mathrm{a}}$. Ana Carolina Magalhães e à funcionária Telma, por toda a ajuda e pelos empréstimos de vidraçarias da Bioquímica. 



\section{AGRADECIMENTO ESPECIAL}

À minha orientadora, Prof. ${ }^{a}$ Dr. ${ }^{a}$ Linda Wang, um grande exemplo de professora, pesquisadora, e principalmente, de ser humano. Muito obrigada pela confiança depositada em mim e pela paciência em transmitir todos os ensinamentos. Foram 5 anos de uma parceria intensa (desde o $3^{\circ}$ ano da graduação até o mestrado) que me fez crescer imensamente como profissional e ser humano. Você tem um coração enorme, está sempre preocupada com os outros e disposta a ajudar todos que estão a sua volta. $\mathrm{O}$ meu pedido especial para Deus é que Ele te faça feliz e

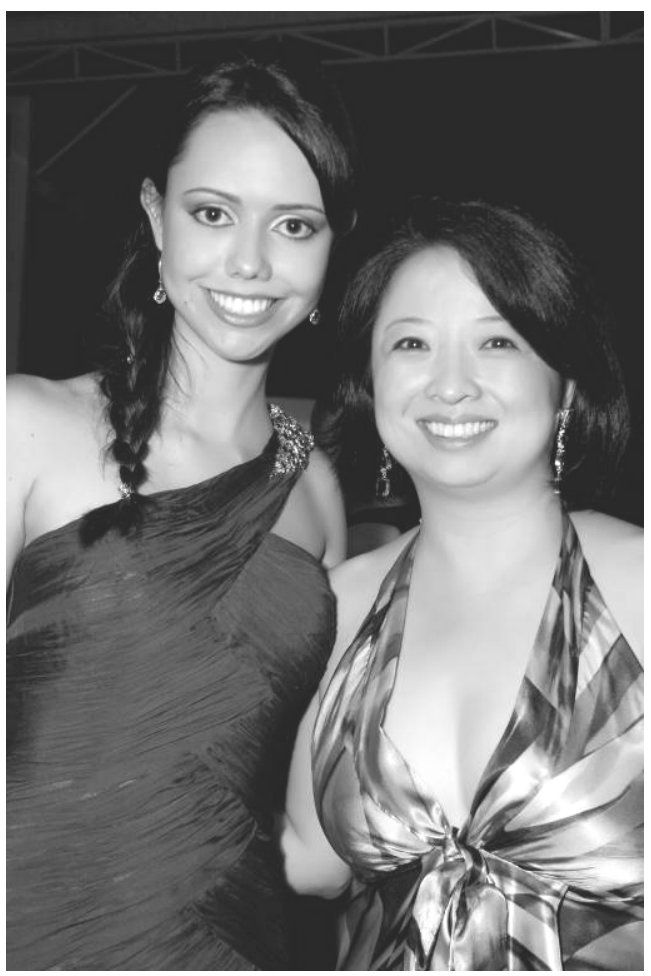
realizada a cada dia. Serei eternamente grata a você! 



\section{AGRADECIMENTOS INSTITUCIONAIS}

Ao Prof. Dr. Marco Antônio Zago, digníssimo Reitor da Universidade de São Paulo;

Ao Prof. Dr. Ignacio Maria Poveda Velasco, Secretário Geral da Universidade de São Paulo;

À Prof ${ }^{a}$. Dra . Maria Aparecida de Andrade Moreira Machado, Diretora da Faculdade de Odontologia de Bauru da Universidade de São Paulo;

Ao Prof. Dr. Guilherme dos Reis Pereira Janson, Presidente da Comissão de PósGraduação da Faculdade de Odontologia de Bauru da Universidade de São Paulo;

À Fundação de Amparo à Pesquisa do Estado de São Paulo (FAPESP), pelo fundamental suporte financeiro concedido para a realização dessa pesquisa (processo: 2013/08902-3). 

“Ora, a fé é a certeza daquilo que esperamos e a prova das coisas que não vemos." 



\section{RESUMO}

Este estudo in vitro avaliou o efeito da adição de rodamina B dissolvida em etanol nas concentrações de $0,02 \mathrm{mg} / \mathrm{mL}$ e $0,10 \mathrm{mg} / \mathrm{mL}$, nas propriedades mecânicas dos sistemas adesivos não simplificados considerados padrão-ouro. 96 coroas de terceiros molares humanos hígidos foram seccionadas transversalmente no terço oclusal para remoção do esmalte e exposição da dentina. Os espécimes foram divididos de acordo com os sistemas adesivos Adper Scotchbond Multi-Purpose (MP) - convencional de três passos ou Clearfil SE Bond (SE) - autocondicionante de dois passos: MP-C e SE-C (MP e SE controles); MP-C1 e SE-C1 (MP e SE com rodamina B 0,02mg/mL); MP-C2 e SE-C2: (MP e SE com rodamina B $0,10 \mathrm{mg} / \mathrm{mL})$. Para o teste de RU, os espécimes $(\mathrm{n}=10)$ foram submetidos ao desgaste com lixas de granulação 320 e 600. A dentina foi tratada de acordo com as instruções de cada fabricante dos sistemas adesivos e restaurada com resina composta Filtek ${ }^{\mathrm{TM}}$ Z250. Após o armazenamento em saliva artificial $\left(7 \mathrm{dias} / 37^{\circ} \mathrm{C}\right)$, os espécimes foram seccionados para obtenção de palitos com $0,64 \mathrm{~mm}^{2}$ de área média e submetidos ao teste de microtração em máquina de teste universal a $0,5 \mathrm{~mm} / \mathrm{min}$, que foram analisados após 7 dias e 6 meses. $\mathrm{O}$ modo de fratura dos espécimes foi analisado com estereomicroscópio digital (x200) e classificado em: adesiva, coesiva em dentina, coesiva em resina e mista. Para o teste de MS, as coroas seccionadas $(n=6)$ foram planificadas com lixa de granulação 600. A dentina foi tratada de acordo com as instruções de cada fabricante dos sistemas adesivos e os espécimes foram mantidos secos em estufa a $37^{\circ} \mathrm{C}$ durante 48 horas. O teste de MS foi realizado utilizando ponta Knoop (Microdurômetro Shimadzu HMV-2), a 10x e carga estática de $25 \mathrm{gF}$ por 10 segundos. Os resultados obtidos foram analisados por análise de variância (ANOVA-2 critérios) e teste de Bonferroni para comparações múltiplas $(\mathrm{p}<0,05)$. A análise de acordo com o tempo foi realizada com o teste de t-student. Os valores médios de RU e desvio padrão $(\mathrm{MPa} \pm \mathrm{dp} ; 7$ dias / 6 meses) foram: MP-C (41,95 $\pm 2,38$ / 22,76 $\pm 3,66)$; MP-C1 (28,02 $\pm 5,12$ /

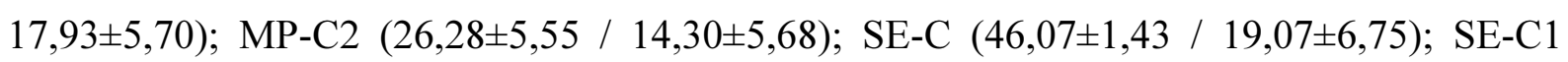
$(37,49 \pm 13,31 / 18,54 \pm 6,71)$; SE-C2 (34,16 $\pm 7,71 / 17,89 \pm 4,87)$. No tempo de 7 dias, os fatores sistema adesivo e concentração de rodamina B foram significantes. Após 6 meses, apenas o fator concentração de rodamina B foi significante. A falha de fratura predominante em todos os grupos foi adesiva. Os valores de MS $(\mathrm{KHN})$ e desvio padrão foram: MP-C $(8,97 \pm 3,85)$; 

MP-C1 (7,33 $\pm 0,99) ;$ MP-C2 (7,17 $\pm 2,45) ;$ SE-C (4,71 $\pm 4,42) ;$ SE-C1 $(4,42 \pm 0,56) ;$ SE-C2 $(3,27 \pm 0,30)$. Na comparação entre os sistemas adesivos, eles diferiram entre si na condição controle e de $0,10 \mathrm{mg} / \mathrm{mL}$. Para cada adesivo, não houve diferença entre as distintas condições de acordo com a adição de rodamina B. Em função dos resultados apresentados, a adição de rodamina B nos sistemas adesivos não simplificados $\mathrm{MP}$ e SE, nas concentrações de $0,02 \mathrm{mg} / \mathrm{mL}$ e $0,10 \mathrm{mg} / \mathrm{mL}$, deve ser incorporada com cautela para que não influencie nas propriedades mecânicas do material.

Palavras-chave: Dentina; Adesivos dentinários; Testes de dureza; Corantes fluorescentes 



\section{ABSTRACT}

\section{Analysis of the effect of addition of Rhodamine B marker on mechanical properties of non-simplified adhesives}

This in vitro study evaluated the effect of addition of rhodamine B dissolved in ethanol in concentrations of $0.02 \mathrm{mg} / \mathrm{mL}$ and $0.10 \mathrm{mg} / \mathrm{mL}$, the mechanical properties of non-simplified adhesive systems. 96 crowns of human third molars were transversely sectioned on the oclusal third to remove the enamel and exposure the dentin. The specimens were divided according to the adhesive systems Adper Scotchbond Multi-Purpose (MP) - 3-step-etch-andrinse or Clearfil SE Bond (SE) - 2-step-self-ecthing: MP-C and SE-C (MP and SE controls); MP-C1 and SE-C1 (MP and SE with $0.02 \mathrm{mg} / \mathrm{mL}$ rhodamine B); MP-C2 and SE-C2: (MP and $\mathrm{SE}$ with $0.10 \mathrm{mg} / \mathrm{mL}$ rhodamine B). For the $\mu$ TBS test, the specimens $(\mathrm{n}=10)$ were ground with 320- to 600-grit silicon carbide paper. The dentin was treated according to the instructions of each manufacturer and restored with composite resin Filtek ${ }^{\mathrm{TM}} \mathrm{Z} 250$. The specimens were stored in artificial saliva $\left(7\right.$ days $\left./ 37^{\circ} \mathrm{C}\right)$, and then sectioned to obtain sticks with an average of $0.64 \mathrm{~mm}^{2}$ area and submitted to $\mu$ TBS test at a universal testing machine at $0.5 \mathrm{~mm} / \mathrm{min}$, which were analyzed immediately after 7 days and 6 months. The mode of fracture of the specimens was analyzed with digital stereomicroscope (x200) and classified as: adhesive, cohesive in dentine, cohesive in resin and mixed. For the SM test, the sectioned crowns $(n=6)$ were flattened with 600-grit silicon carbide paper. The dentin was treated according to the manufacturer's instructions for each adhesive system and the specimens were stored in dry condition at $37^{\circ} \mathrm{C}$ during 48 hours. The SM test was performed with Knoop indenter (Shimadzu HMV-2 hardness tester), at $10 \mathrm{x}$ and $25 \mathrm{gF}$ of load for 10 seconds. The results were analyzed by two-way analysis of variance tests and the Bonferroni test for multiple comparisons $(\mathrm{p}<0.05)$. The analysis regarding time was checked with t-student test. The mean $\mu \mathrm{TBS}$ and standard deviation (MPa $\pm \mathrm{dp} ; 7$ days / 6 months) were: MP-C $(41.95 \pm 2.38$ / 22.76 \pm 3.66$) ; \mathrm{MP}-\mathrm{C} 1$ (28.02 \pm 5.12 / 17.93 \pm 5.70$)$; MP-C2 (26.28 \pm 5.55 / $14.30 \pm 5.68)$; SE-C (46.07 \pm 1.43 / 19.07 \pm 6.75$)$; SE-C1 (37.49 $\pm 13.31 / 18.54 \pm 6.71)$; SE-C2 $(34.16 \pm 7.71 / 17.89 \pm 4.87)$. In the immediate time, the adhesive system and rhodamine B concentration factors were significant. After 6 months, only the rhodamine B concentration was a significant factor. The predominant failure in all groups was adhesive. The values of 

SM and standard deviation were: MP-C (8.97 \pm 3.85$)$; MP-C1 (7.33 \pm 0.99$) ; \quad$ MP-C2 (7.17 \pm 2.45$)$; SE-C (4.71 \pm 4.42$)$; SE-C1 (4.42 \pm 0.56$)$; SE-C2 (3.27 \pm 0.30$)$. In the comparison between the adhesive systems, they were significantly different for the conditions control and $0.10 \mathrm{mg} / \mathrm{mL}$. For each adhesive systems, there was no difference between the different conditions according to the addition of rhodamine B. Regarding the shown results, addition of rodhamine $\mathrm{B}$ in non-simplified adhesives $\mathrm{MP}$ and $\mathrm{SE}$, in the concentrations of $0.02 \mathrm{mg} / \mathrm{mL} \mathrm{e}$ $0.10 \mathrm{mg} / \mathrm{mL}$ must be carefully added to avoid implications to the mechanical properties of the materials.

Key words: Dentin; Dentin-bonding agents; Hardness tests; Fluorescent dyes 



\section{LISTA DE ILUSTRAÇÕES}

- FIGURAS

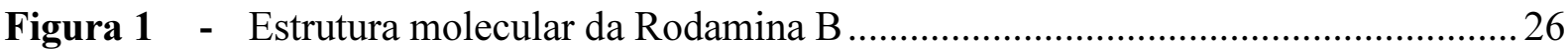

Figura 2 - Balança analítica com legibilidade de $0,01 \mathrm{mg}$.............................................. 41

Figura 3 - Rodamina B depositada no interior do balão volumétrico com o auxílio de espátula de metal ......................................................................... 41

Figura 4 - Solução de estoque de rodamina B em etanol após homogeneização

Figura 5 - Coleta da solução de estoque e deposito dentro do tubo

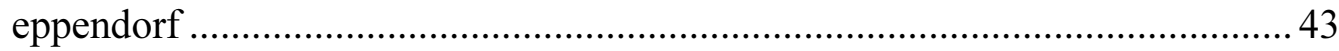

Figura 6 - Rodamina B após completa evaporação do etanol .......................................... 43

Figura 7 - Adesivo depositado dentro do tubo eppendorf ................................................ 43

Figura 8 - Tubo colocado em um amalgamador por 15 segundos para completa homogeneização ........................................................................... 43

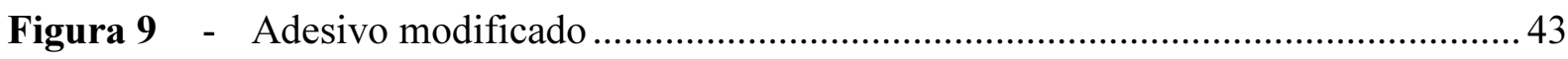

Figura 10 - Corte do dente utilizando disco diamantado ................................................. 45

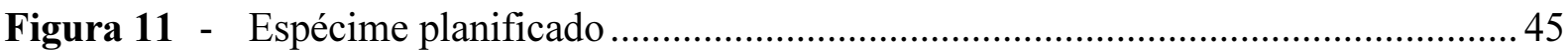

Figura 12 - Condicionamento com ácido fosfórico 37\% durante 15 segundos para os grupos MP-C, MP-C1 e MP-C2 ........................................ 46

Figura 13 - Aplicação do respectivo primer para todos os grupos ..................................... 46

Figura 14 - Aplicação do adesivo para os grupos controles ................................................. 47

Figura 15 - Aplicação do adesivo para os grupos experimentais …................................... 47

Figura 16 - Aplicação de incrementos de resina................................................................. 47

Figura 17 - Restauração finalizada apresentando $4,5 \mathrm{~mm}$ de altura ................................... 47

Figura 18 - Secção do conjunto dente-restauração ……….................................................... 48

Figura 19 - Obtenção de palito com $0,8 \mathrm{~mm}$ X 0,8mm de dimensões ................................ 48

Figura 20 - Palito fixado pelas extremidades com adesivo à base de cianocrilato ao dispositivo tipo Bencor.

Figura 21 - Estereomicroscópio digital utilizado (DINO-LITEplus digital microscope) ...................................................................................... 50

Figura 22 - Segmento de coroa ( $3 \mathrm{~mm}$ de altura) fixado em base de acrílico

Figura 23 - Microdurômetro Shimadzu HMV-2 …......................................................... 51 



\section{LISTA DE TABELAS E QUADROS}

\section{- TABELAS}

Tabela 1 - Valores de média (MPa) e desvio padrão de resistência de união dos grupos testados nos tempo de 7 dias e 6 meses

Tabela 2 - Distribuição das fraturas em porcentagem de acordo com a concentração de rodamina B no tempo de 7 dias 56

Tabela 3 - Distribuição das fraturas em porcentagem de acordo com a concentração de rodamina $\mathrm{B}$ no tempo de 6 meses

Tabela 4 - Valores de média e desvio padrão da microdureza de superfície dos grupos

- QUADROS

Quadro 1 - Características do corante rodamina B ..........................................................26

Quadro 2 - Materiais utilizados e suas principais características...................................... 40

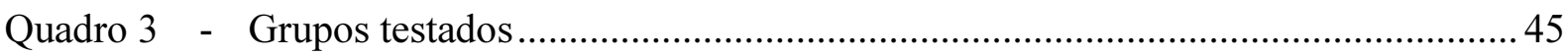

Quadro 4 - Instruções para a aplicação dos sistemas adesivos, segundo bula dos fabricantes 



\section{LISTA DE ABREVIATURAS, SIGLAS E SÍMBOLOS}

\begin{tabular}{|c|c|}
\hline$\%$ & Por cento \\
\hline$<$ & Menor \\
\hline${ }^{\circ} \mathbf{C}$ & Graus Celsius \\
\hline 10-MDP & 10-metacriloiloxidecil di-hidrogênio fosfato \\
\hline Bis-EMA & Bisfenol A Etoxilato Dimetacrilato \\
\hline Bis-GMA & Bisfenol A Glicidil Metacrilato \\
\hline gf & Grama força \\
\hline $\mathrm{g} / \mathrm{mol}$ & Grama por mol \\
\hline HEMA & 2-Hidroxi-etilmetacrilato \\
\hline Kgf & Quilograma força \\
\hline MCVL & Microscopia confocal de varredura a laser \\
\hline MET & Microscopia eletrônica de transmissão \\
\hline mg & Miligrama \\
\hline $\mathbf{m g} / \mathbf{m L}$ & Miligrama por mililitro \\
\hline $\mathbf{m L}$ & Mililitro \\
\hline $\mathbf{m m}$ & Milímetro \\
\hline $\mathbf{m m}^{2}$ & Milímetro quadrado \\
\hline $\mathbf{m m} / \mathbf{m i n}$ & Milímetro por minuto \\
\hline MP & Adper ${ }^{\mathrm{TM}}$ Scotchbond ${ }^{\mathrm{TM}}$ Multi-Purpose \\
\hline MPa & Megapascal \\
\hline MVT & Microscópio de varredura tandem \\
\hline $\mathbf{m W} / \mathbf{c m}^{2}$ & Miliwatt por centímetro quadrado \\
\hline $\mathbf{P}$ & Nível de significância \\
\hline SE & Clearfil $^{\mathrm{TM}}$ SE Bond \\
\hline Ta & Tipo adesiva \\
\hline Ted & Tipo coesiva em dentina \\
\hline Ter & Tipo coesiva em resina composta \\
\hline $\mathbf{T m}$ & Tipo mista \\
\hline UDMA & Uretano Dimetacrilato \\
\hline $\mathbf{x}$ & Vezes \\
\hline
\end{tabular}





\section{SUMÁRIO}

1 INTRODUÇÃO.

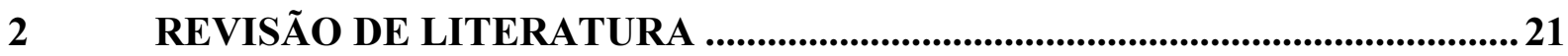

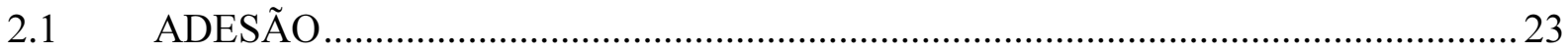

2.2 MARCADORES FLUORESCENTES E SISTEMAS ADESIVOS ……………........25

2.3 TESTE DE RESISTÊNCIA DE UNIÃO POR MICROTRAÇÃO ............................29

2.4 MICRODUREZA DE SUPERFÍCIE ..................................................................

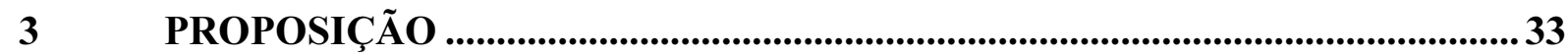

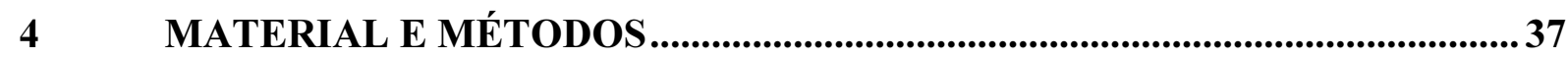

4.1 AVALIAÇÃO PELO COMITÊ DE ÉTICA EM PESQUISA EM

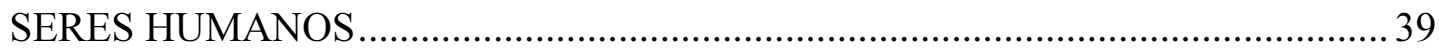

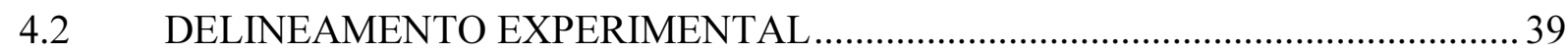

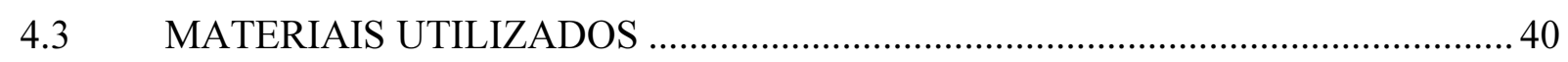

4.4 ADIÇÃO DE RODAMINA B AOS SISTEMAS ADESIVOS ……………………... 44

4.5 PREPARO DOS ESPÉCIMES PARA TESTE DE

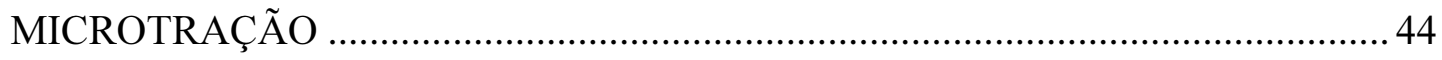

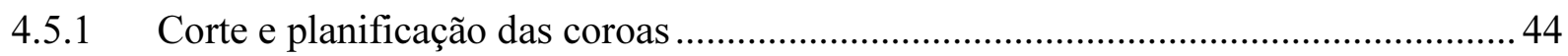

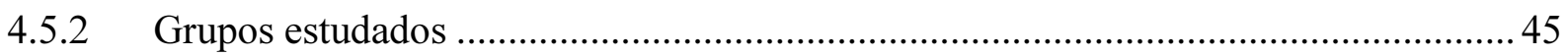

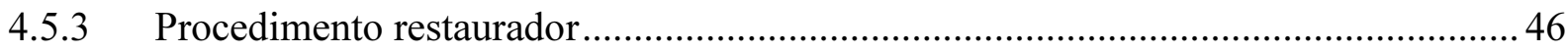

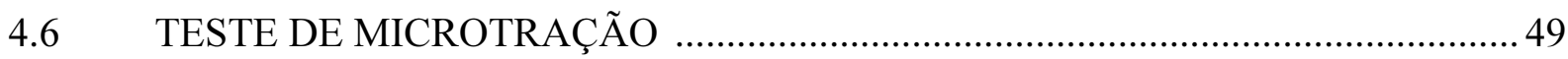

4.7 PREPARO DOS ESPÉCIMES PARA TESTE DE MICRODUREZA DE SUPERFÍCIE ………………………………………....5 50

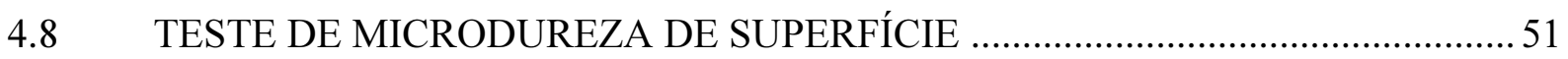

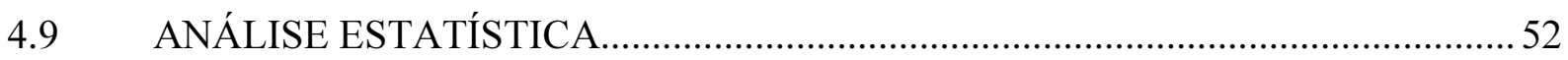

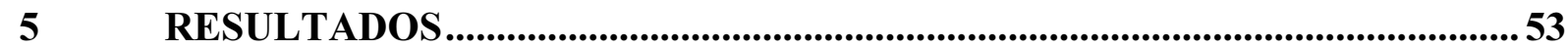

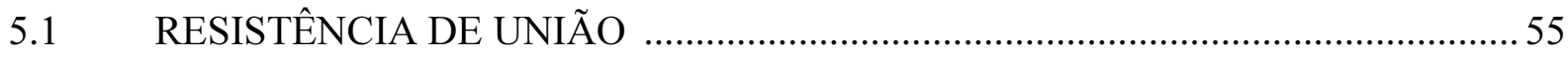

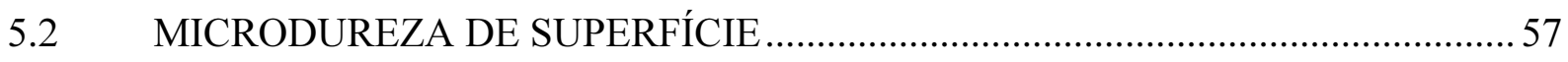

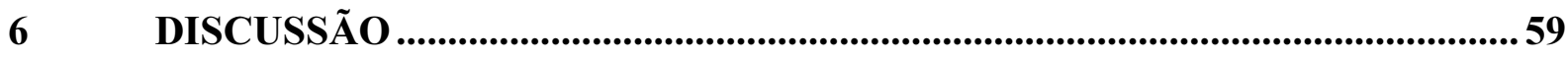

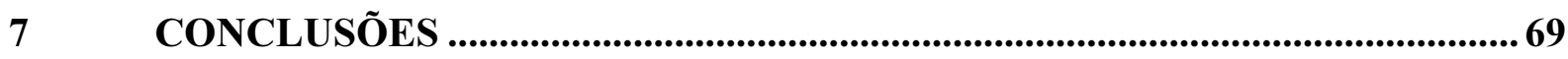

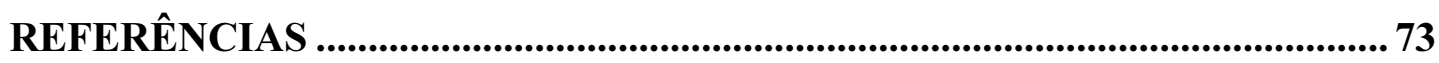

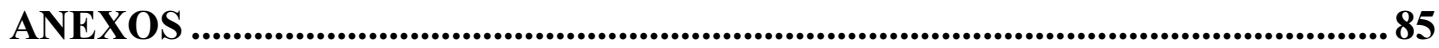





\section{INTRODUÇÃO}





\section{INTRODUÇÃO}

A longevidade clínica das restaurações adesivas depende de uma série de fatores, desde o adequado estabelecimento da camada híbrida, que sustenta a interface adesiva, até as condições em que essas restaurações são realizadas (PASHLEY et al., 2011).

A camada híbrida é essencialmente estabelecida por um processo micromecânico de retenção do material adesivo no substrato dentário (NAKABAYASHI; KOJIMA; MASUHARA, 1982; PASHLEY et al., 2011). Uma vez que o substrato dentinário é predominante, sua complexidade e sua natureza determinam a necessidade de produtos que possam ser mais estáveis e resistentes à degradação em meio úmido e dinâmico (FABRE et al., 2007; PASHLEY et al., 2011).

Em estudos mais minuciosos dessa interação, métodos visuais como o emprego da técnica de microscopia confocal de varredura a laser (MCVL) aliada a marcadores fluorescentes têm sido amplamente realizados (WATSON, 1991; D'ALPINO et al., 2006a; FOXTON et al., 2008; FRANCISCONI et al., 2009). Dentre esses marcadores, a rodamina B corresponde a um dos corantes mais frequentemente empregados (D'ALPINO et al., 2006b). Por ser solúvel em água e solventes orgânicos, a rodamina B pode ser utilizada em baixas concentrações, o que se justifica devido a propriedades como o seu alto coeficiente de extinção molar, que permite maior aproveitamento (WATSON, 1991).

Acrescentando-se rodamina B a diferentes sistemas adesivos, tem sido possível observar, em experimentos in vitro, aspectos da micromorfologia da camada híbrida, como a extensão, espessura e quantidade de tags de resina. Essa capacidade permitiu seu emprego no diagnóstico de possíveis defeitos e alterações na interface adesiva, como, por exemplo, a ocorrência de zonas incompletas de infiltração de monômeros na dentina desmineralizada, permitindo que as fibrilas de colágeno permaneçam expostas e desprotegidas (GRIFFITHS, 1999; KREJCI et al., 1999; SAURO et al., 2008; WALTER et al., 2008; SAMPAIO et al., 2011).

Além da técnica convencional de adição desse marcador, seu uso concomitantemente a outros marcadores, durante a preparação dos espécimes, foi proposto para permitir melhor visualização de detalhes por contraste. Isso é possível devido à diferença de valor dos 
comprimentos de onda de excitação e de emissão de cada marcador. Assim, Watson (1989) incorporou rodamina $\mathrm{B}$ e fluoresceína em constituintes diferentes de um sistema adesivo. Sauro et al. (2008) estudaram a micropermeabilidade em vários sistemas por meio de uma técnica de dupla impregnação, depositando soluções de rodamina B e de nitrato de prata na câmara pulpar de dentes extraídos.

Diante das várias possibilidades de aplicação, os ensaios com rodamina B apresentamse como estratégias promissoras no estudo da adesão.

Aos poucos, algumas limitações de cada técnica de microscopia e suas implicações na análise da interface de união passaram a ser estudadas. Watson (1997) preocupou-se com alguns fatores que poderiam interferir na técnica, como o processo de fotobranqueamento e a influência da quantidade de marcador fluorescente dissolvida nos sistemas adesivos para o estudo da interface. $\mathrm{O}$ autor destacou que o excesso de marcador fluorescente em sistemas adesivos poderia provocar a redução na intensidade da fluorescência, e desse modo, afetaria a viabilidade precisa da interface.

Embora o foco do uso dos marcadores fluorescentes seja o estudo da interface, poucos são os trabalhos que se preocupam com as consequências nas demais propriedades físicoquímicas. D’Alpino et al. (2006b) evidenciaram a influência da concentração de rodamina B em relação a algumas propriedades de um adesivo simplificado previamente marcado. $\mathrm{O}$ grau de conversão dos monômeros em polímeros e a resistência de união do material representam duas das propriedades essenciais a serem aferidas, uma vez que o corante absorve luz. Assim, há a possibilidade de se interferir na quantidade de luz transmitida aos fotoiniciadores durante a fotopolimerização do adesivo, dependendo da concentração de corante adotada na solução (D'ALPINO et al, 2006b). Além disso, durante as fases de teste, a homogeneidade e a estabilidade das soluções modificadas, bem como a adequada fixação nos espécimes investigados, são fatores relevantes para a interpretação final dos resultados (SCHUPBACH et al., 1997; WATSON, 1997). Os primers possuem solventes em sua composição que otimizam a capacidade de molhamento do substrato pelo seu potencial hidrofílico, melhorando a infiltração da resina fluida na dentina desmineralizada e úmida (GRIFFITHS et al., 1999). Quando marcadores, como a rodamina B, são incorporados por dissolução nos solventes, há a possibilidade de sua lixiviação. 
Consoante exposto, D’Alpino et al. (2006b) procuraram sistematizar uma metodologia para o emprego de rodamina B dissolvida em um sistema adesivo convencional de dois passos, atentando para uma série de variáveis que poderiam influenciar a interpretação das imagens obtidas por microscopia, bem como as propriedades do material resinoso testado.

Outra questão relevante é que a maioria dos trabalhos acerca do tema utilizou a adição direta do pó do marcador ao sistema adesivo em estudo, o que poderia representar uma mistura mais frágil quanto ao correto proporcionamento. Entretanto, essa técnica teve o propósito de investigar o modo mais comumente realizado. A diluição prévia do marcador a um solvente puro como o etanol viabilizaria a inserção de quantidades mais reduzidas e mais padronizadas, com menor chance de interferir em outras propriedades (BIM JÚNIOR, 2013).

Nenhum dos trabalhos revisados incluiu, no delineamento experimental, a análise da influência de distintas concentrações de marcadores fluorescentes em propriedades mecânicas dos sistemas adesivos, sejam convencionais ou autocondicionantes. Por isso, não se tem a certeza de que as concentrações do marcador podem alterar propriedades de um sistema resinoso, prejudicando a adesão entre o substrato dentário e o componente resinoso e, assim, diminuindo a longevidade da restauração. Presume-se que os sistemas adesivos devam ser modificados com as menores quantidades de marcador fluorescente capazes de permitir uma adequada análise microscópica e que não alterem as propriedades mecânicas do sistema resinoso.

Pensando-se na validação da associação da rodamina $\mathrm{B}$ a sistemas adesivos considerados padrão-ouro, os quais são os sistemas não simplificados convencional de três passos ou auto-condicionante de dois passos, novas investigações tornam-se necessárias, a fim de que os próximos estudos envolvendo rodamina $\mathrm{B}$ e sistemas adesivos possam se respaldar em uma metodologia sistematizada e com a menor concentração possível desse agente fluorescente. 



\section{REVISÃO DE LITERATURA}





\section{REVISÃO DE LITERATURA}

\subsection{ADESÃO}

O surgimento dos sistemas adesivos, materiais restauradores que se aderem ao substrato dentário, revolucionou a Odontologia restauradora durante o século XX, com a introdução de técnicas adesivas mais conservadoras e efetivas. Entretanto, se por um lado o sucesso da adesão ao esmalte foi alcançado, um grande desafio ainda permanece em relação à dentina (PERDIGÃO, 2010), que é um substrato complexo e menos previsível do que a adesão ao esmalte (REIS et al., 2008).

O estudo pioneiro relacionando a adesão à estrutura dentária foi realizado por Buonocore (1955). O autor observou que o prévio condicionamento do esmalte com ácido fosfórico a $85 \%$ em restaurações realizadas com resina composta favoreceu a força de união, já que criou micro-retenções, aumentando dessa forma, a área de contato da superfície do esmalte. Mertz-Fairhurst et al. (1998) comprovaram a eficácia da adesão em esmalte por meio de um acompanhamento clínico durante 10 anos. Foi observado que as restaurações de resinas compostas com margens em esmalte apresentavam longevidade clínica comparável às restaurações convencionais de amálgama.

Ao contrário da adesão em esmalte, a adesão em dentina teve um desenvolvimento mais lento e, somente em 1982, Nakabayashi, Kojima e Masuhara propuseram a utilização de monômeros resinosos contendo grupos hidrofílicos capazes de penetrar entre as fibrilas de colágeno desmineralizadas, formando a posteriormente denominada "camada híbrida". Desse modo, o condicionamento ácido da estrutura dentária, associado ao conceito de camada híbrida, consiste atualmente no principal mecanismo de adesão às estruturas do dente. (PASHLEY et al., 2011). A técnica proposta para a obtenção da adesão de resinas compostas às estruturas dentárias consiste na aplicação dos sistemas adesivos. Atualmente, os sistemas adesivos podem ser classificados de acordo com o tratamento da smear layer e do número de passos operatórios.

O sistema adesivo convencional de três passos apresenta ácido, primer e adesivo, os quais são fornecidos em frascos separados e representam diferentes fases do tratamento da dentina. Segundo Van Meerbeek et al. (2005) e De Munck et al. (2012), o adesivo 
convencional de três passos continua a ser considerado o padrão-ouro entre os adesivos convencionais, devido a fatores relacionados à eficácia, à durabilidade e à compatibilidade com os demais materiais. O sistema convencional de dois passos contém, além do ácido como etapa distinta, um material que cumpre as funções de primer e adesivo, como simplificação do sistema de três etapas.

Os sistemas adesivos autocondicionantes são aqueles em que o condicionamento com ácido fosfórico não é realizado como etapa separada, mas simultaneamente à aplicação dos monômeros, os quais possuem características ácidas capazes de realizar a modificação por desmineralização controlada da estrutura dentária. Existem dois tipos de sistemas adesivos autocondicionantes: de dois passos, em que o primer ácido é aplicado, seguido por um adesivo hidrofóbico; e de passo único, que combina as funções de ácido, primer e adesivo.

Apesar das versões simplificadas do sistema adesivo reduzirem os passos clínicos e o tempo de trabalho, esses adesivos comportam-se como membranas permeáveis capazes de atrair água da dentina para a interface adesivo/resina composta, provocando a formação de bolhas e o comprometimento da união da resina com o adesivo (SANARES et al., 2001; CARVALHO et al., 2004). Posteriormente, a água do meio externo pode entrar em contato com a interface adesiva (nonoinfiltração), colaborando para a sua degradação (TAY; PASHLEY; YOSHIYAMA, 2002). Por outro lado, os sistemas adesivos autocondicionantes de dois passos apresentam resultados mais satisfatórios, devido à presença da camada de adesivo hidrofóbico que provoca a impermeabilização do primer hidrofílico, postergando a nanoinfiltração e reduzindo a permeabilidade da dentina (CARVALHO, 2004; CHERSONI et al., 2004).

A partir dessas perspectivas, diversos trabalhos vêm demonstrando e reforçando o uso de sistemas autocondicionantes em análises variadas. Hamouda et al. (2010) analisaram algumas propriedades dos sistemas adesivos autocondicionantes de dois passos, autocondicionantes de um passo e convencional de dois passos. Nesse trabalho, o sistema adesivo autocondicionante de dois passos apresentou melhores resultados quando comparado com os demais sistemas adesivos testados. Chandra et al. (2013) avaliaram a microinfiltração em restaurações classe $\mathrm{V}$ de resina composta, utilizando sistemas adesivos autocondicionantes de dois passos e de um passo. Os autores concluíram que os sistemas adesivos autocondicionantes não simplificados apresentam redução na infiltração marginal quando comparados com os adesivos autocondicionantes simplificados. 
Em análises clínicas, o aspecto promissor também é verificado, como no trabalho de Van Dijken (2010), que realizou um estudo prospectivo de 8 anos para avaliar a retenção clínica dos sistemas adesivos autocondicionantes de dois passos e convencional de dois passos na dentina. Os resultados mostraram que o adesivo autocondicionante apresentou melhor retenção clínica ao longo do tempo, quando comparado ao adesivo convencional.

Algumas marcas comerciais de sistemas adesivos autocondicionantes de dois passos apresentam em sua composição o 10-MDP (10-metacriloxidecil dihidrogênio fostato), que é uma substância capaz de se ligar quimicamente ao cálcio, formando fosfato de cálcio, o qual aumenta a efetividade da adesão desses sistemas (VAN MEERBEEK et al., 2011). Conforme De Munck et al. (2012), os melhores resultados de adesão são obtidos pelos sistemas adesivos convencionais de três passos e pelos sistemas adesivos autocondicionantes de dois passos. Peumans et al. (2005) realizaram uma revisão sistemática sobre a eficácia clínica dos sistemas adesivos contemporâneos. Os sistemas adesivos convencionais de três passos e autocondicionante de dois passos apresentaram desempenho clínico superior quando comparados aos convencionais de dois passos e autocondicionante de um passo. Por isso, os autores concluíram que a simplificação dos sistemas adesivos influencia na redução da sua eficácia clínica. Apesar da constatação da superioridade dos sistemas adesivos não simplificados, esses sistemas ainda apresentam falhas, principalmente quando as margens da restauração situam-se na dentina. A adesão em dentina ainda apresenta fraca ligação entre a resina composta e o dente, especialmente devido à degradação hidrolítica da camada híbrida (SPENCER et al., 2010), o que torna a interface adesiva, ainda, um dos principais focos de investigação.

\subsection{MARCADORES FLUORESCENTES E SISTEMAS ADESIVOS}

O estudo da morfologia da interface de união, por ser o fundamento da adesão dentária, requer análises mais precisas, que podem ser feitas por meio da microscopia, na qual as estruturas envolvidas e seus aspectos morfológicos e de distribuição podem ser observados e, até mesmo, mensurados (VAN MEERBEEK et al., 1993; SAURO et al., 2008). Em 1982, Nakabayashi, Kojima e Masuhara analisaram a formação da camada híbrida e de tags de resina por meio de fotomicrografias de microscopia eletrônica de varredura (MEV). Anos após, Nakabayashi (1985) realizou a mesma análise por meio da microscopia eletrônica de 
transmissão (MET). Desde então, esses tipos de microscopia vêm contribuindo para uma melhor compreensão da adesão em substratos dentários (VAN MEERBEEK et al., 1993; SAURO et al., 2008). Na aplicação da microscopia, o emprego de recursos mais aprimorados que permitissem não apenas a visualização de superfície, mas também mais internamente, promoveu a possibilidade de melhor detalhamento das análises e o entendimento da interação material-substrato. A microscopia confocal de varredura a laser (MCVL) destaca-se por apresentar capacidade para uma melhor análise morfológica da interface de união, aliada à vantagem de exigir um preparo relativamente simples dos espécimes, permitindo um correto estudo da interface de adesão (WATSON, 1991, 1997). Assim, a MCVL pode ser usada para visualizar sistema adesivo sobre a superfície dentinária e para localizar, com precisão, os tags de resina e a camada híbrida (ARRAIS et al., 2009). Para isso, a associação de agentes fluorescentes é necessária. Nesse caso, agentes, como a rodamina B, têm sido usados para a marcação química de materiais resinosos (WATSON, 1989; GRIFFITHS; WATSON, 1995; D’ALPINO et al., 2006b; BITTER et al., 2009).

A molécula da rodamina $\mathrm{B}$ e algumas características de maior interesse são apresentadas a seguir.

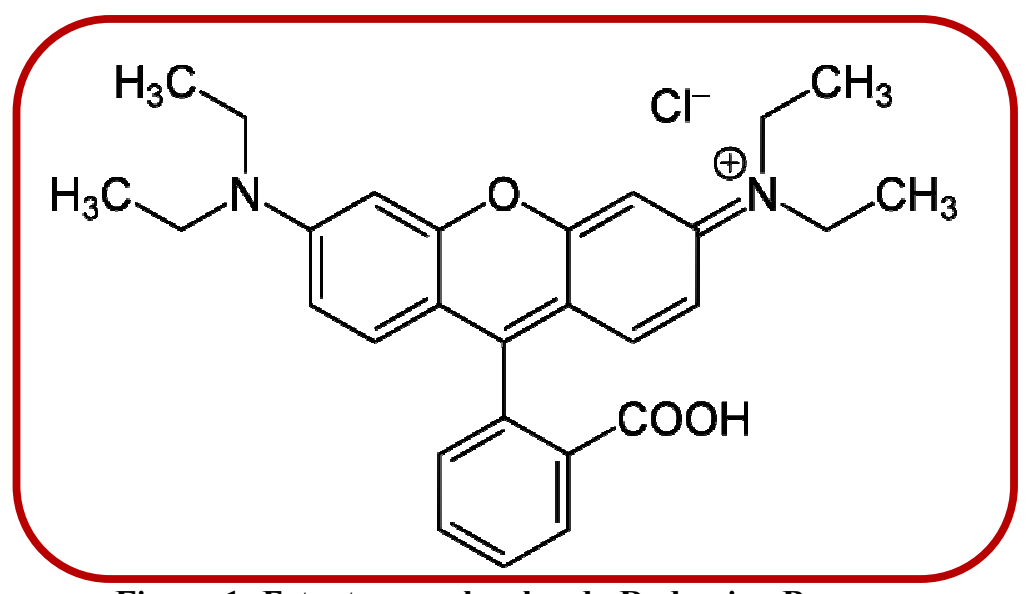

Figura 1: Estrutura molecular da Rodamina B

Quadro 1: Características do corante rodamina B

\begin{tabular}{|c|c|}
\hline CARACTERISTICA & DESCRIÇÃO \\
\hline Fórmula molecular & C28H31N203CL \\
\hline Peso molecular & 479,02 \\
\hline Cor & Pó vermelho violeta ou cristais verdes \\
\hline Solubilidade em água & Solúvel \\
\hline Solubilidade em outros solventes & Álcool, benzeno e éter \\
\hline
\end{tabular}


Os fluorocromos utilizados para essa finalidade devem ser bem misturados aos sistemas adesivos a fim de assegurar total dissolução e homogeneidade. Essa é uma das características que torna a rodamina B interessante nesse emprego. Esses fluorocromos têm sido incorporados, principalmente, de forma direta no frasco do sistema adesivo, durante o processo de fabricação (SCHUPBACH; KREJCI; LUTZ, 1997; WATSON, 1997), ou por meio de uma alíquota de álcool, o que otimizaria sua incorporação (BIM JÚNIOR, 2013). Em uma das primeiras pesquisas acerca da incorporação de marcadores fluorescentes aos sistemas adesivos (WATSON; BOYDE, 1987), a rodamina B foi acrescentada no sistema adesivo Scotchbond, empregado na restauração de cavidades cervicais em terceiros molares extraídos, com o objetivo de analisar a interface dente-restauração por meio da microscopia de varredura tandem (MVT). Com isso, os autores concluíram que o marcador fluorescente, rodamina B, facilitou a visualização do sistema adesivo. Contudo, a qualidade das imagens era inferior a daquelas produzidas com a MCVL anos depois (PIOCH et al., 1997; SAMPAIO et al., 2011).

Mesmo que ao microscópio de varredura tandem tenha sido o primeiro equipamento utilizado no estudo da interface de adesão com marcadores fluorescentes, novos estudos começaram a utilizar a MCVL (WATSON, 1991, GRIFFITHS; WATSON; SHERRIFF, 1999). A MVT convencional utilizava uma lâmpada como fonte de iluminação, enquanto a MCVL trazia a novidade da iluminação com lasers, na qual ocorre a seleção de feixes de luz com comprimentos de ondas coincidentes ou, pelo menos, muito próximos do máximo comprimento de onda de excitação de cada marcador fluorescente. Portanto, excelentes resultados têm sido alcançados com a MCVL (DING et al., 2010) para avaliação da interface de união.

O emprego de lasers também apresentava algumas limitações para a MCVL. Isso se justifica na medida em que há o risco de danificar as amostras biológicas, devido à potência do laser, e de provocar a destruição fotoquímica do marcador fluorescente (DENK; STRICKLER; WEBB, 1990; DIASPRO; ROBELLO, 2000).

A partir dessa discussão, D’Alpino et al. (2006b) preocuparam-se com o modo de adição dos marcadores fluorescentes aos sistemas adesivos, o que poderia influenciar a interpretação das imagens obtidas por microscopia, bem como as propriedades do material resinoso testado. Na literatura científica, existe uma falta de consenso acerca da quantidade de marcador adicionada aos componentes resinosos. Em muitos estudos, a concentração do marcador não é mencionada na metodologia, ou os dados são inconclusivos. D’Alpino et al. 
(2006a) estabeleceram correlações entre a concentração de rodamina B e algumas propriedades do sistema adesivo Adper Single Bond. Concluíram que a quantidade do marcador fluorescente influencia na resistência de união à dentina. A partir desse estudo, passou a ser adotada a concentração de $0,16 \mathrm{mg} / \mathrm{mL}$ de rodamina $\mathrm{B}$ em pesquisas posteriores. Esse marcador fluorescente era incorporado de forma direta no sistema adesivo e sempre utilizando, especificamente, o mesmo sistema adesivo (FRANCISCONI et al., 2009; SAMPAIO et al., 2011; CASAS-APAYCO et al., 2014). Todavia, essa concentração, por mais que fosse considerada segura, não era confirmada como sendo a melhor relação entre a concentração do marcador e a intensidade de fluorescência necessária para a análise microscópica.

Bim Júnior (2013) sistematizou um método de adição de rodamina B aos sistemas adesivos, bem como, avaliou concentrações mínimas de rodamina B nos sistemas adesivos viáveis para a adequada análise morfológica da interface de adesão, utilizando a microscopia confocal de varredura a laser. Os sistemas adesivos Adper Scotchbond Multi-Purpose e Clearfil SE Bond foram modificados com rodamina B em cinco concentrações: $0,5 \mathrm{mg} / \mathrm{mL}$, $0,10 \mathrm{mg} / \mathrm{mL}, 0,02 \mathrm{mg} / \mathrm{mL}, 0,004 \mathrm{mg} / \mathrm{mL}$ e $0,0008 \mathrm{mg} / \mathrm{mL}$. Devido ao fato dos sistemas adesivos escolhidos serem não simplificados, o autor foi instigado a encontrar uma técnica que possibilitasse melhor homogeneidade na mistura, uma vez que esses sistemas mais viscosos apresentam resistência durante a mistura de forma direta. Dessa maneira os adesivos foram modificados por meio da técnica de proporcionamento, na qual o marcador fluorescente foi adicionado aos componentes resinosos a partir de soluções de rodamina B em etanol.. Após a investigação, concluiu que é possível analisar microscopicamente a dentina utilizando sistemas adesivos modificados com rodamina B em concentrações menores que as mencionadas na literatura, sendo que $0,02 \mathrm{mg} / \mathrm{mL}$ foi a concentração que apresentou melhores resultados em relação ao contraste e à saturação nas fotomicrografias, independente do sistema utilizado.

Nenhum dos trabalhos revisados incluiu, no delineamento experimental, a análise da influência de distintas concentrações de marcadores fluorescentes em propriedades mecânicas dos sistemas adesivos, sejam convencionais ou autocondicionantes. Por isso, não se tem a certeza de que as concentrações do marcador podem alterar propriedades de um sistema resinoso, prejudicando a adesão entre o substrato dentário e o componente resinoso e, assim, diminuindo a longevidade da restauração. Presume-se que os sistemas adesivos devam ser modificados com as menores quantidades de marcador fluorescente capazes de permitir uma 
adequada análise microscópica e que não alterem as propriedades mecânicas do sistema resinoso.

\subsection{TESTE DE RESISTÊNCIA DE UNIÃO POR MICROTRAÇÃO}

As pesquisas acerca dos sistemas adesivos fundamentam-se, principalmente, em avaliações laboratoriais e clínicas da interação material/substrato dentário, quais sejam: resistência de união, morfologia da interface e durabilidade da união (SANO et al., 1999; BRESCHI et al., 2003; HASHIMOTO et al., 2003; CARRILHO et al., 2005; TOLEDANO et al., 2006; DING et al., 2009). Apesar dos ensaios clínicos apresentarem melhor resposta às hipóteses da pesquisa, longo tempo necessário, fatores relacionados a questões éticas e ao alto custo (SUDSANGIAM; VAN NOORT, 1999) dificultam, ou mesmo inviabilizam, esses estudos. Por conseguinte, testes laboratoriais têm sido utilizados cada vez mais como parâmetro de avaliação do desempenho de sistemas adesivos (SUDSANGIAM; VAN NOORT, 1999; VAN MEERBEEK et al., 2003).

Pesquisas atuais têm avaliado a qualidade de interface de união por meio de testes de resistência de união, nanoindentação, tenacidade de fratura, análise de distribuição de fraturas na interface. Essa qualidade de interface de união pode estar relacionada às características tanto do sistema adesivo testado, quanto das técnicas empregadas (GARCIA et al., 2002).

A resistência de união dos sistemas adesivos aos substratos dentários foi, por muitos anos, avaliada quantitativamente por meio dos testes mecânicos de tração e cisalhamento (SCHREINER et al., 1998). Contudo, Pashley et al. (1995) já observavam o grande número de limitações que poderiam influenciar nos testes de adesão, como o número crescente de fraturas coesivas.

Sano et al. (1994) realizaram um estudo sobre a resistência de união em pequenas áreas do substrato, formando palitos com área de secção transversal de $2 \mathrm{~mm}^{2}$. Esse foi o estudo pioneiro com a metodologia do teste de microtração. Os autores concluíram que a resistência de união é dependente da área obtida, sendo que quanto menor a área, maior o valor de resistência obtido. Além disso, os autores encontraram menor ocorrência de falhas coesivas nos espécimes com área reduzida. A partir desse estudo, o teste de microtração 
tornou-se uma das metodologias mais utilizadas para testar a resistência de união dos sistemas adesivos ao substrato dentário (DE MUNCK et al., 2005; VAN MEERBEEK et., 2010).

Em diversas situações, estudos têm utilizado o teste de microtração para análise da resistência de união dos sistemas adesivos à dentina, considerando vários fatores que pudessem exercer desempenhos diferenciados. Esse teste tem permitido resultados que colaboram na técnica adesiva da rotina adotada na clínica. Assim, alguns trabalhos são apontados na sequência a fim de exemplificação. Garcia et al. (2009) avaliaram a resistência de união de sistemas adesivos em diferentes condições de evaporação do solvente. Aboushelib (2011) investigou a influência da contaminação por saliva na resistência à microtração de um sistema adesivo. Mendez et al. (2012) pesquisaram o efeito do armazenamento em água na resistência de união por microtração de sistemas adesivos. Mobarak, El-Deeb e Yousry (2013) avaliaram a influência de diferentes líquidos de simulação de pressão intrapulpar na resistência de união de sistemas adesivos à dentina. Salvio et al. (2013) realizaram um estudo para avaliar a resistência de união de sistemas adesivos de acordo com a interação com a dentina. Chen et al. (2014) utilizaram o teste de microtração para investigar os efeitos de corrente elétrica na interface de união adesivo/dentina. Mena-Serrano et al. (2014) compararam diferentes formas de aplicação de sistemas adesivos à dentina, por meio do teste de microtração. Zheng et al. (2014) avaliaram o efeito das metaloproteinases na resistência à microtração de sistemas adesivos. Diante disso, os trabalhos apontam que o teste é válido para análises comparativas entre produtos ou técnicas, permitindo padronização de análise. 


\subsection{MICRODUREZA DE SUPERFÍCIE}

Muitas pesquisas têm utilizado os testes de microtração e microcisalhamento para avaliar a resistência de união de uma restauração de resina composta ao substrato dentário (SCHERRER et al., 2010). Entretanto, a dureza é uma propriedade mecânica do material restaurador que pode estar relacionada à efetividade da resistência de união e, se avaliadas comparativamente, podem responder mais detalhadamente aos questionamentos sobre o mecanismo de adesão. Para a medição da microdureza são utilizados equipamentos chamados de microdurômetros, descrito por Boyer em 1987. Eles são compostos por um centro de cargas, um penetrador que transmite a carga a uma superfície por um determinado tempo e um microscópio com lentes objetivas para visualizar as indentações.

No estudo de materiais restauradores, a dureza tem sido aplicada para a análise de propriedades relacionadas com a composição, o grau de polimerização e a degradação superficial do material (TURBINO et al., 2011). Os tipos de teste de dureza utilizados na Odontologia, ao envolver substratos dentários e polímeros, são as durezas do tipo Vickers e Knoop (SILVA et al., 2012; BOTTINO et al., 2013).

A dureza Vickers foi desenvolvida por Smith e Sandland (1925) e apresenta um indentador em forma de pirâmide de diamante de base quadrada. Para cargas muito pequenas, a dureza Vickers pode variar de uma carga para outra, devendo sempre ser mencionada a carga utilizada. O penetrador Vickers tem sido muito utilizado nos testes de microdureza com cargas menores que $1 \mathrm{kgf}$.

Outro teste muito utilizado é o Knoop (1939), que apresenta um penetrador em forma de pirâmide alongada, sendo que a diagonal maior é três vezes maior que a diagonal menor. Souza (1982) concluiu que, para uma mesma carga, a medição torna-se mais precisa e ocorre uma menor influência da recuperação elástica, principalmente para cargas maiores que $300 \mathrm{gf}$. A profundidade da impressão Knoop é menor que a metade da profundidade causada pela impressão Vickers com a mesma carga. Já a área de uma impressão Knoop é cerca de 15\% da área de uma impressão Vickers com a mesma carga. Como os testes de microdureza possuem cargas muito baixas (menores que $300 \mathrm{gf}$ ) as impressões são muito pequenas. Esse tamanho reduzido pode dificultar a mensuração precisa da diagonal maior da impressão devido à complexidade de se localizar as pontas da diagonal. 
Para a realização do teste para microestruturas, Boyer (1987) desenvolveu os testes de microdureza com cargas menores de $1000 \mathrm{gf}$. O tamanho da indentação está relacionado com o tempo de indentação e com a carga aplicada. Para os testes de microdureza são utilizados os indentadores Knoop e Vickers. .

$\mathrm{Na}$ aplicação da microdureza de superfície nos sistemas adesivos, trabalhos têm sido utilizados para aferir a microdureza diante de diversos desafios, analisando o efeito sobre a polimerização de sistemas adesivos (BASTING; SERRA; RODRIGUES, 2002; SILVA et al., 2012; BOTTINO et al., 2013). Exemplificando, da Silva et al. (2010) avaliaram o efeito de sistemas adesivos contendo fluoretos e monômero antibacteriano na interface de união, por meio do teste de microdureza. A análise da microdureza foi realizada com indentador Knoop, com carga de 10 gf e endentações de 5 segundos. Silva et al. (2012) determinaram se a microdureza dos sistemas adesivos convencionais Adper Single Bond 2 (SB), One-step (OS) e Adper Scotchbond Multi-Purpose (MP) pode ser afetada pelo tratamento prévio da dentina. Para essa finalidade, utilizaram a microdureza Knoop, com carga de $25 \mathrm{gf}$ e indentações de 6 segundos. Bottino et al. (2013), também aplicando a microdureza de superfície pela ponta Knoop, aferiram a influência da inserção de nanotubos em diferentes sistemas adesivos. Martins et al. (2014), avaliaram o efeito da adição de micropartículas de vidro de borosilicato de bário em um sistema adesivo simplificado experimental. Para isso, uma das variáveis de resposta foi a microdureza Knoop, com carga de 10 gf e indentações de 15 segundos.

Então, a amplitude do emprego desse recurso pode ser verificada em situações distintas para análise de propriedades dos sistemas adesivos. 



\section{PROPOSIÇÃO}

Este estudo in vitro teve como objetivo avaliar o efeito da adição de duas concentrações de rodamina $\mathrm{B}$ nas propriedades mecânicas dos sistemas adesivos não simplificados Adper $^{\mathrm{TM}}$ Scotchbond ${ }^{\mathrm{TM}}$ Multi-Purpose (MP) e Clearfili ${ }^{\mathrm{TM}}$ SE Bond (SE), por meio da resistência de união e da microdureza de superfície. As hipóteses nulas consideradas foram de que:

1- Não há diferença na resistência de união à dentina dos sistemas adesivos não simplificados puros comparados aos mesmos sistemas após a dissolução de rodamina B nas concentrações de $0,02 \mathrm{mg} / \mathrm{mL}$ e $0,10 \mathrm{mg} / \mathrm{mL}$.

2- Não há diferença na resistência de união utilizando sistemas adesivos não simplificados puros comparados aos mesmos sistemas após a dissolução de rodamina $\mathrm{B}$ nas concentrações de $0,02 \mathrm{mg} / \mathrm{mL}$ e $0,10 \mathrm{mg} / \mathrm{mL}$, em função do tempo (7 dias ou 6 meses).

3- Não há diferença na microdureza de superfície utilizando sistemas adesivos não simplificados puros comparados aos mesmos sistemas após a dissolução de rodamina B nas concentrações de $0,02 \mathrm{mg} / \mathrm{mL}$ e $0,10 \mathrm{mg} / \mathrm{mL}$. 




\section{MATERIAL E MÉTODOS}

\subsection{AVALIAÇÃO PELO COMITÊ DE ÉTICA EM PESQUISA EM SERES HUMANOS}

Este trabalho foi submetido à apreciação junto ao Comitê de Ética em Pesquisa em Seres Humanos da Faculdade de Odontologia de Bauru, FOB-USP, sendo aprovado com o CAAE 17406313.6.0000.5417 (anexo 1).

\subsection{DELINEAMENTO EXPERIMENTAL}

Este trabalho foi desenvolvido através de uma pesquisa in vitro. O delineamento experimental apresentou três fatores: sistema adesivo (dois níveis - Adper ${ }^{\mathrm{TM}}$ Scotchbond ${ }^{\mathrm{TM}}$ Multi-Purpose e Clearfil ${ }^{T M}$ SE Bond), condição (três níveis - controle, 0,02 mg de rodamina $\mathrm{B} / \mathrm{mL}$ de adesivo e $0,10 \mathrm{mg} / \mathrm{mL}$ ) e tempo (dois níveis -7 dias e 6 meses). As variáveis de resposta foram a análise de resistência de união por microtração e de microdureza de superfície.

Em função das diferentes variáveis de resposta envolvidas, esse delineamento foi dividido nas duas etapas a seguir:

Etapa A - Avaliação da resistência de união, por meio de testes de microtração, prevendo que as proporções de rodamina B não alterem significativamente a variável de resposta analisada, em relação aos valores obtidos para os respectivos grupos controle. Para a realização dessa etapa, os dentes foram aleatoriamente divididos em 6 grupos (MP-C, MP-C1 MP-C2, SE-C, SE-C1, SE-C2), de acordo com a concentração de rodamina B e o tipo de sistema adesivo utilizado, descritos no Quadro 3.

Etapa B - Avaliação da microdureza de superfície dos sistemas MP e SE após a adição de rodamina $B$ nas concentrações de $0,02 \mathrm{mg} / \mathrm{mL}$ e $0,10 \mathrm{mg} / \mathrm{mL}$. 


\subsection{MATERIAIS UTILIZADOS}

Os principais materiais necessários para a realização do estudo estão descritos no quadro abaixo.

Quadro 2 - Materiais utilizados e suas principais características

\begin{tabular}{|c|c|c|c|}
\hline MATERIAL & COMPOSIÇÃ̃O & FABRICANTE & CLASSIFICAÇÃO \\
\hline $\begin{array}{l}\text { Adper }^{\mathrm{TM}} \text { Scotchbond }^{\mathrm{TM}} \\
\text { Multi-Purpose (Primer) } \\
\text { Adper }^{\mathrm{TM}} \text { Scotchbond } \\
\text { Muti-Purpose (adesivo) }^{\mathrm{TM}}\end{array}$ & $\begin{array}{l}\text { HEMA, copolímero de ácido } \\
\text { polialcenóico, água } \\
\text { Bis-GMA, HEMA, } \\
\text { canforoquinona }\end{array}$ & $\begin{array}{c}\text { 3M ESPE, Saint Paul, } \\
\text { Minnesota, Estados } \\
\text { Unidos }\end{array}$ & $\begin{array}{c}\text { Sistema adesivo } \\
\text { convencional de três passos }\end{array}$ \\
\hline $\begin{array}{l}\text { Clearfil }^{\mathrm{TM}} \text { SE Bond } \\
\text { (Primer) }^{\text {Primer }} \\
\text { Clearfil }^{\mathrm{TM}} \text { SE Bond } \\
\text { (Adesivo) }^{\text {(Adesion }}\end{array}$ & $\begin{array}{l}\text { 10-MDP, HEMA, dimetacrilato } \\
\text { hidrófilo,conforoquinona, N-N- } \\
\text { Dietanol-P-Toluidina, água } \\
\text { 10-MDP, HEMA, Bis-GMA, } \\
\text { dimetacrilato hidrófobo, } \\
\text { canforoquinona, N-N-Dietanol- } \\
\text { P-Toluidina, sílica coloidal }\end{array}$ & $\begin{array}{c}\text { Kuraray Co. Ltda., Osaka, } \\
\text { Japão }\end{array}$ & $\begin{array}{c}\text { Sistema adesivo } \\
\text { autocondicionante de dois } \\
\text { passos }\end{array}$ \\
\hline $\begin{array}{c}\text { Condicionador Dental } \\
\text { Gel }\end{array}$ & Gel de ácido ortofosfórico a $37 \%$ & $\begin{array}{c}\text { Dentsplay Indústria e } \\
\text { Comércio Ltda., Rio de } \\
\text { Janeiro, Brasil }\end{array}$ & $\begin{array}{l}\text { Condicionador ácido de } \\
\text { esmalte e dentina }\end{array}$ \\
\hline Filtek $^{\mathrm{TM}} \mathbf{Z 2 5 0}$ & $\begin{array}{c}\text { Matriz orgânica: } \\
\text { Bis-GMA, UDMA, Bis-EMA, } \\
\text { canforoquinona } \\
\text { Parte inorgânica: zircônia/sílica } \\
(82 \% \text { em peso, } 60 \% \text { em volume; } \\
\text { partículas } 0,6 \mu \mathrm{m})\end{array}$ & $\begin{array}{c}\text { 3M ESPE, Saint Paul, } \\
\text { Minnesota, Estados } \\
\text { Unidos }\end{array}$ & $\begin{array}{c}\text { Resina composta micro- } \\
\text { híbrida }\end{array}$ \\
\hline Rodamina B & $\mathrm{C}_{28} \mathrm{H}_{31} \mathrm{CIN}_{2} \mathrm{O}_{3}(\mathrm{M}=479,01 \mathrm{~g} / \mathrm{mol})$ & $\begin{array}{l}\text { Sigma-Aldrich-Ghemie- } \\
\text { GmbH, Gillingham/Nwe } \\
\text { Rd, United Kingdom }\end{array}$ & Marcador Fluorescente \\
\hline $\begin{array}{l}\text { Álcool Etílico Absoluto } \\
\text { P.A. }\end{array}$ & Etanol 99,5 oGL & $\begin{array}{c}\text { Dinâmica Química } \\
\text { Contemporânea, } \\
\text { Diadema, São Paulo, } \\
\text { Brasil }\end{array}$ & $\begin{array}{c}\text { Etanol anidro com alto grau } \\
\text { de pureza }\end{array}$ \\
\hline
\end{tabular}

10-MDP: 10-metacriloiloxidecil di-hidrogênio fosfato Bis-EMA: Bisfenol A glicidil metacrilato etoxilato Bis-GMA: Bisfenol-A glicidil metacrilato

HEMA: 2-Hidroxietil metacrilato

UDMA: Uretano dimetacrilato

Informações fornecidas pelo fabricante 


\subsection{ADIÇÃO DE RODAMINA B AOS SISTEMAS ADESIVOS}

O marcador fluorescente rodamina B (Rhodamine B ${ }^{\circledR}$, Sigma-Aldrich Chemie GmbH, Gillingham/Nwe Rd - UK) foi adicionado nas duas concentrações aos sistemas adesivos MP e SE, sendo inicialmente preparada uma solução de estoque de rodamina B em etanol $(0,50$ $\mathrm{mg} / \mathrm{mL}$ ). Para a obtenção dessa solução, foram pesados 50 miligramas de pó de rodamina $\mathrm{B}$ em balança analítica com legibilidade de 0,01 mg (GR-202, AeD ENGINEERING, INC., São José, CA, EUA - Figura 2). A rodamina B foi depositada cuidadosamente no interior de um balão volumétrico de 100mL com o auxílio de uma espátula de metal (Figura 3). Em seguida, o mesmo balão foi preenchido com etanol anidro até a marcação de $100 \mathrm{~mL}$. Após o fechamento do recipiente, ele foi agitado manualmente por trinta segundos e a agitação foi complementada com um banho ultrassônico (Ultracleaner USC-1600 ${ }^{\mathrm{A}}$, Unique, Indaiatuba, SP, Brasil) durante cinco minutos (Figura 4), para a completa homogeneização da rodamina $\mathrm{B}$.

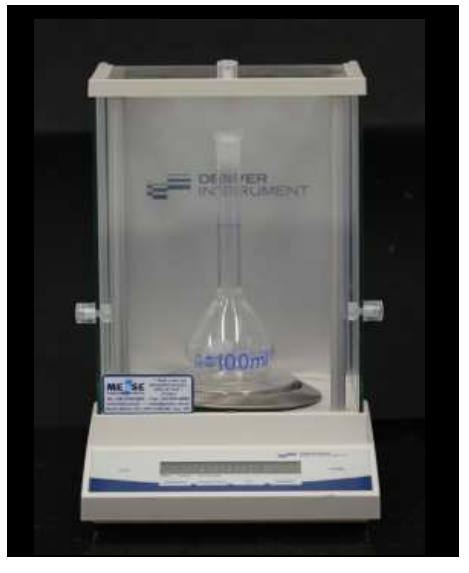

Figura 2: Balança analítica com legibilidade de $0,01 \mathrm{mg}$

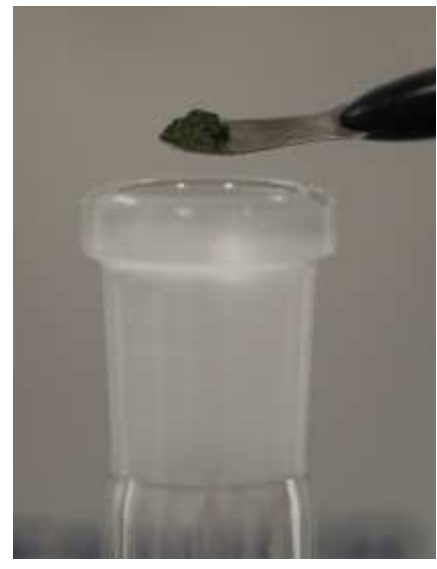

Figura 3: Rodamina B depositada no interior do balão volumétrico com o auxílio de espátula de metal

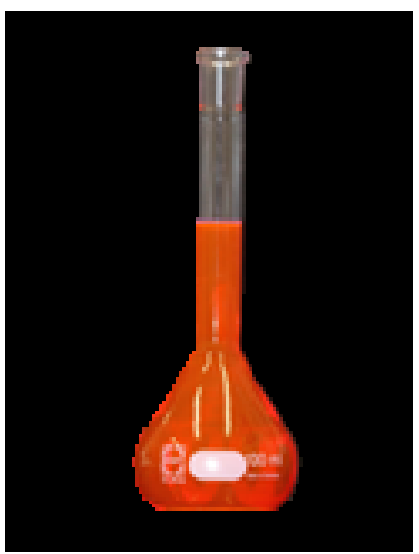

Figura 4: Solução de estoque de rodamina $B$ em etanol após homogeneização

A massa de rodamina B acrescentada a certo volume de adesivo foi extraída de alíquotas precisas da solução de estoque de etanol. Essa massa em cada alíquota foi calculada através da equação $\mathrm{m}_{(\mathrm{ROD}-\mathrm{AL})}=\mathrm{c}_{(\mathrm{ROD}-\mathrm{AL})} \cdot \mathrm{v}_{(\mathrm{AL})}$, em que $\mathrm{m}_{(\mathrm{ROD}-\mathrm{AL})}$ é a massa de rodamina $\mathrm{B}$ na alíquota, $\mathrm{c}_{(\mathrm{ROD}-\mathrm{AL})}$ é a concentração de rodamina $\mathrm{B}$ na alíquota e $\mathrm{v}_{(\mathrm{AL})}$ é volume da alíquota.

Por outro lado, a massa de rodamina B em certo volume de adesivo pode ser calculada pela equação $\mathrm{m}_{(\mathrm{ROD}-\mathrm{AD})}=\mathrm{c}_{(\mathrm{ROD}-\mathrm{AD})} \cdot \mathrm{v}_{(\mathrm{AD})}$, em que $\mathrm{m}_{(\mathrm{ROD}-\mathrm{AD})}$ é a massa de rodamina $\mathrm{B}$ no adesivo, $\mathrm{c}_{(\mathrm{ROD}-\mathrm{AD})}$ é a concentração de rodamina $\mathrm{B}$ no adesivo e $\mathrm{v}_{(\mathrm{AD})}$ é o volume de adesivo. 
Como $\mathrm{m}_{(\mathrm{ROD}-\mathrm{AL})}$ e $\mathrm{m}_{(\mathrm{ROD}-\mathrm{AD})}$ são iguais, tem-se a equação empregada no preparo dos adesivos modificados $\mathrm{c}_{(\mathrm{ROD}-\mathrm{AL})} \cdot \mathrm{v}_{(\mathrm{AL})}=\mathrm{c}_{(\mathrm{ROD}-\mathrm{AD})} \cdot \mathrm{v}_{(\mathrm{AD})}$.

Para a modificação dos sistemas adesivos MP e SE utilizou-se 0,05 mL de cada adesivo. Dessa maneira, nos grupos MP-C1 e SE-C1, com uma micropipeta (Transferpette S, BRAND GmbH +CO KG, Wertheim, Alemanha), coletou-se 0,002 $\mathrm{mL}$ da solução de estoque. A alíquota foi imediatamente depositada em um tubo eppendorf de $5 \mathrm{~mL}$ (Figura 5). O tubo aberto foi colocado em uma estufa (Estufa 502, Fanem, São Paulo, SP, Brasil) à temperatura de $65^{\circ} \mathrm{C}$ para a evaporação do etanol anidro, durante 30 minutos. Após a evaporação do etanol, retirou-se o tubo da estufa (Figura 6). Com o auxílio de uma micropipeta, $0,05 \mathrm{~mL}$ do sistema adesivo foi coletado diretamente do frasco fornecido pelo fabricante. Após a coleta, o adesivo foi depositado dentro do tubo eppendorf (Figura 7) e o tubo foi coberto por um papel alumínio para evitar a ativação precoce da rodamina B. A fim de proporcionar a completa homogeneização, o tubo foi colocado em um amalgamador durante 15 segundos (Figura 8). Assim, o adesivo modificado estava adequado para a sua aplicação (Figura 9).

O mesmo procedimento foi feito para os grupos MP-C2 e SE-C2. Entretanto, foi coletado $0,01 \mathrm{~mL}$ da solução de estoque. 


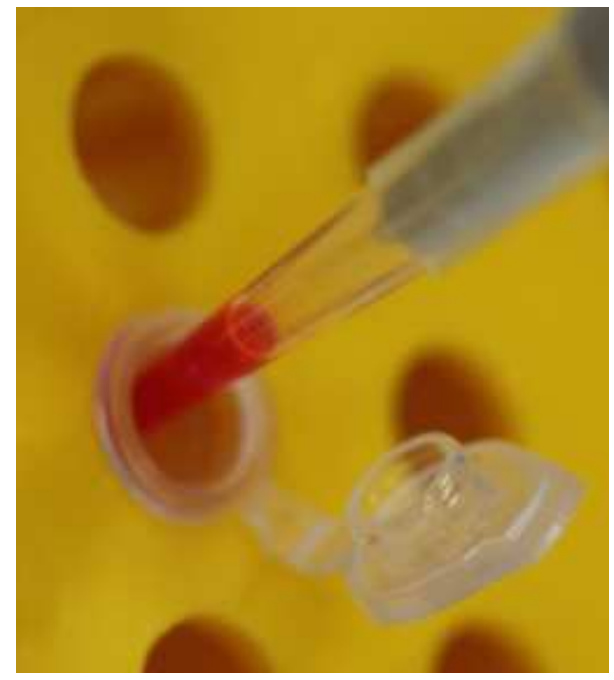

Figura 5: Coleta da solução de estoque e depósito dentro do tubo eppendorf

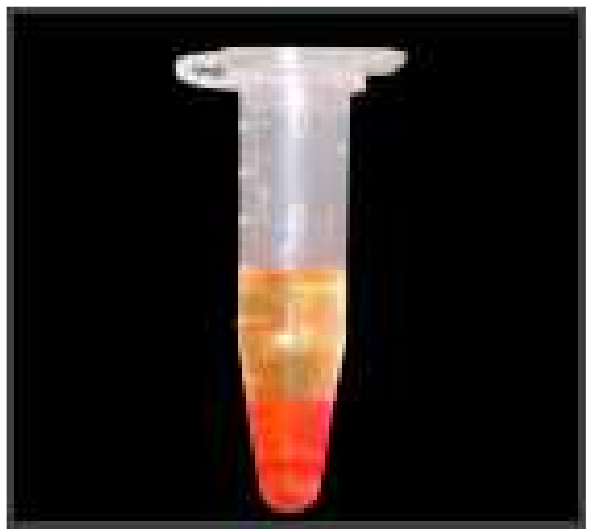

Figura 7: Adesivo depositado dentro do tubo eppendorf

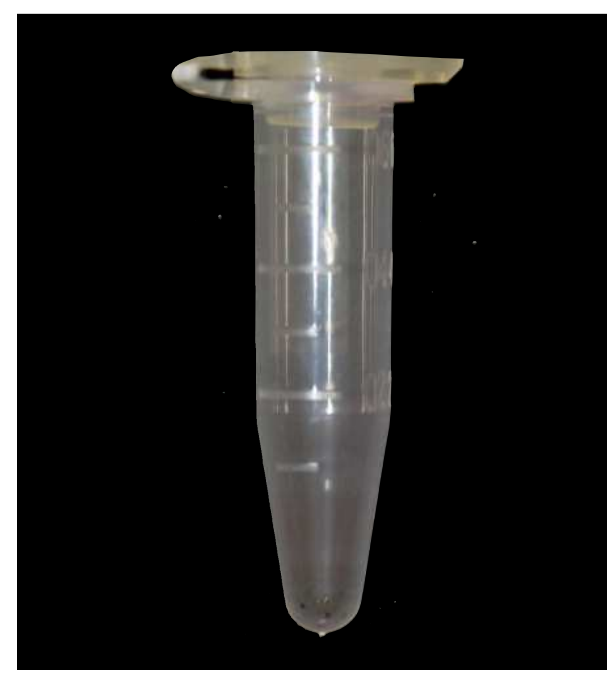

Figura 6: Rodamina $\mathrm{B}$ após completa evaporação do etanol

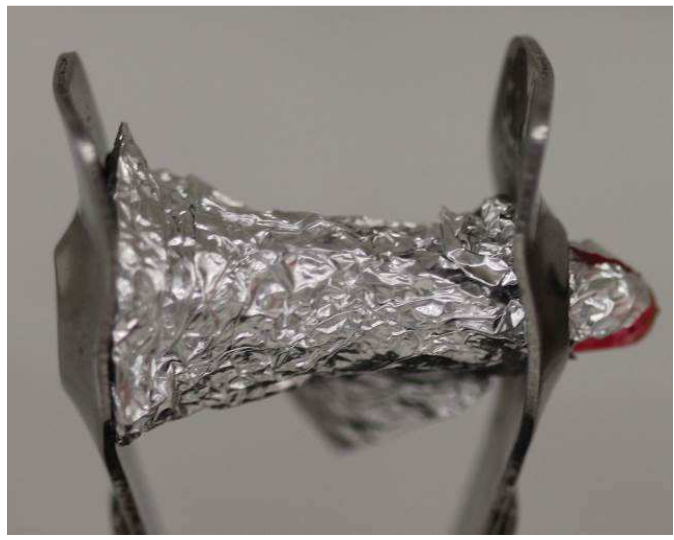

Figura 8: Tubo colocado em um amalgamador por 15 segundos para completa homegeneização

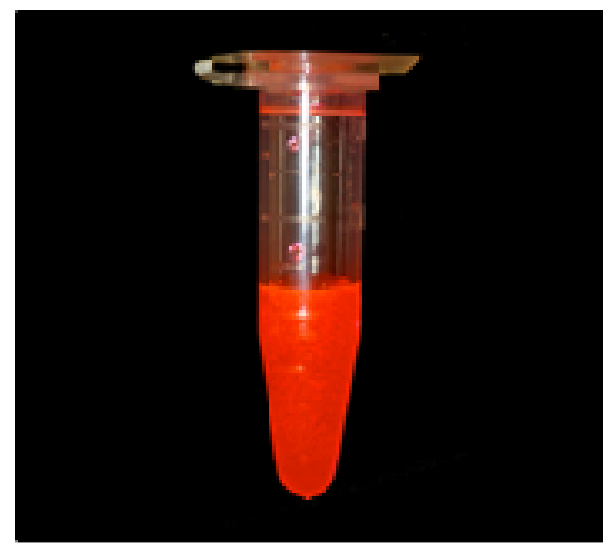

Figura 9: Adesivo modificado 


\subsection{OBTENÇÃO DOS DENTES HUMANOS}

Para este estudo foram utilizados noventa e seis dentes terceiros molares extraídos por indicação odontológica. Os dentes foram obtidos por doações de cirurgiões-dentistas que atendem em consultórios particulares, mediante assinatura dos termos de doação de dentes (Anexos 2 e 3), de acordo com a regulamentação vigente do Comitê de Ética em Pesquisa em Seres Humanos dessa Universidade.

Após a extração, os dentes foram limpos com curetas (Duflex 55G, SS White Artigos Dentários Ltda., Rio de Janeiro, RJ - Brasil) para remoção de restos de tecidos periodontais e, posteriormente, armazenados em solução de timol a $0,1 \%$, renovada semanalmente, na qual ficaram imersos durante todo o período até o preparo dos espécimes.

\subsection{PREPARO DOS ESPÉCIMES PARA TESTE DE MICROTRAÇÃO}

\subsubsection{Corte e padronização das coroas}

Sessenta dentes foram selecionados para a realização do teste de microtração. Os dentes foram fixados com cera pegajosa (Asfer Indústria Química Ltda, São Caetano do Sul, SP, Brasil) em um dispositivo para adaptação na máquina de corte manual Isomet Low Speed Saw (South Bay Technology Inc., Buehler, Lake Bluff, IL, EUA) e seccionados transversalmente no terço oclusal, com disco diamantado (Extec Corp - 102mm X 0,3mm X 12,7mm, Enfield, CT, USA) em baixa velocidade e sob refrigeração com água, a fim de se remover o esmalte da face oclusal e expor a superfície de dentina necessária para os procedimentos adesivos/restauradores (Figuras 10 e 11).

Para padronização das superfícies de dentina, os espécimes foram submetidos à ação de desgaste em uma politriz metalográfica (Aropol 2V, Arotec S.A. Industria e Comércio Cotia, SP, Brasil), de modo que a face de dentina exposta estivesse em contato com a lixa e paralela a esta. Primeiramente, para a remoção de eventuais remanescentes de esmalte, empregou-se a lixa de carbeto de silício de granulação 320 (Carbimet Paper Discs, 30-5108320, Buehler, Lake Bluff, IL, EUA) sob baixa rotação e com refrigeração com água, substituída por outra nova periodicamente. Então, para a planificação final da superfície de dentina, bem como para simular a formação de smear layer, foi utilizada lixa de carbeto de silício com granulação 600 (Carbimet Paper Discs, 30-5108-320, Buehler, Lake Bluff, IL, EUA). 


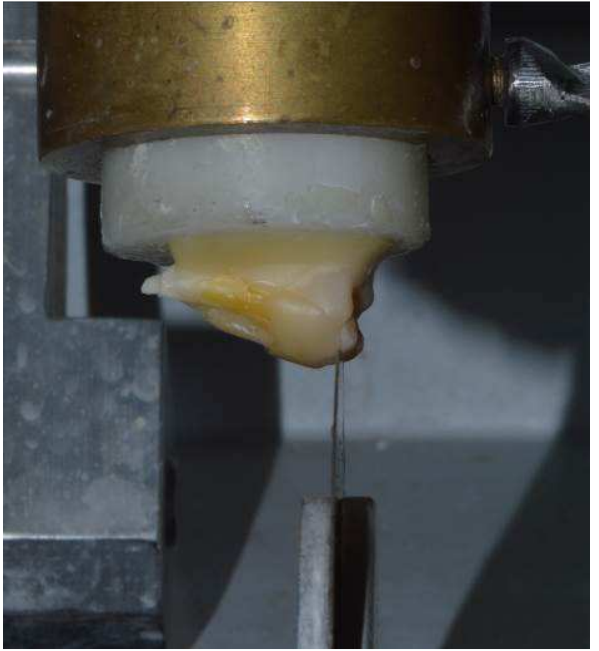

Figura 10: Corte do dente utilizando disco diamantado

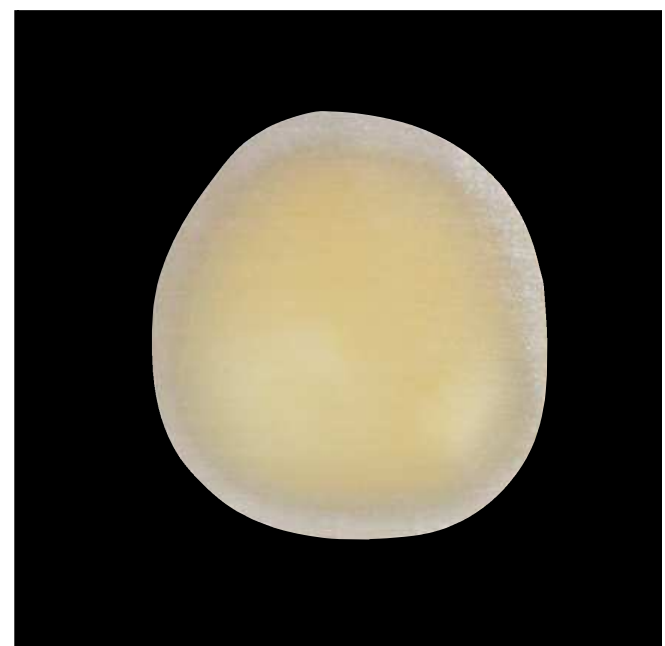

Figura 11: Espécime planificado

\subsubsection{Grupos estudados}

Após o preparo padronizado dos espécimes, os sessenta selecionados foram divididos aleatoriamente em seis grupos nomeados MP-C MP-C1 MP-C2, SE-C, SE-C1 e SE-C2, a fim de receberem tratamento com sistema adesivo de acordo com o Quadro 3 e restaurados com resina composta $(\mathrm{RC})$.

Quadro 3 - Grupos testados

\begin{tabular}{|c|c|}
\hline GRUPOS & DESCRIÇÃO \\
\hline MP-C & Dentes restaurados com sistemas adesivos MP em sua composição original \\
\hline MP-C1 & $\begin{array}{l}\text { Dentes restaurados com sistema adesivo MP, cujo adesivo se apresentou } \\
\text { modificado pela adição de } 0,02 \text { miligramas de rodamina B por mililitro de fluido }\end{array}$ \\
\hline MP-C2 & $\begin{array}{l}\text { Dentes restaurados com sistema adesivo MP, cujo adesivo se apresentou } \\
\text { modificado pela adição de } 0,10 \text { miligramas de rodamina B por mililitro de fluido }\end{array}$ \\
\hline SE-C & Dentes restaurados com sistemas adesivos SE em sua composição original \\
\hline SE-C1 & $\begin{array}{l}\text { Dentes restaurados com sistema adesivo SE, cujo adesivo se apresentou modificado } \\
\text { pela adição de } 0,02 \text { miligramas de rodamina B por mililitro de fluido }\end{array}$ \\
\hline SE-C2 & $\begin{array}{l}\text { Dentes restaurados com sistema adesivo SE, cujo adesivo se apresentou modificado } \\
\text { pela adição de } 0,10 \text { miligramas de rodamina B por mililitro de fluido }\end{array}$ \\
\hline
\end{tabular}




\subsubsection{Procedimento restaurador}

Previamente à realização do procedimento adesivo/restaurador, os espécimes tiveram a superfície exposta de dentina lavada com jato de água abundante e seca com jato de ar. As instruções para a aplicação de cada sistema adesivo, incluindo a etapa de condicionamento ácido do substrato dentinário, estão descritas no Quadro 4 (Figuras 12 a 15). Cada sistema adesivo foi fotoativado com o aparelho fotoativador LED, Radii-cal 2 (SDI, Victoria, Bayswater, Austrália) de intensidade de $1.000 \mathrm{~mW} / \mathrm{cm}^{2}$.

Quadro 4 - Instruções para a aplicação dos sistemas adesivos, segundo bula dos fabricantes

\begin{tabular}{|c|c|}
\hline SISTEMA ADESIVO & TÉCNICA DE APLICAÇÃO \\
\hline $\begin{array}{c}\text { Adper }^{\mathrm{TM}} \text { Scotchbond }^{\mathrm{TM}} \\
\text { Multi-Purpose Plus } \\
\text { (MP) }\end{array}$ & $\begin{array}{l}\text { 1- Condicionar a superfície de dentina durante } 15 \text { segundos com ácido } \\
\text { fosfórico a } 37 \% \text {; } \\
\text { 2- Enxaguar com jato de água abundante por } 15 \text { segundos; } \\
\text { 3- Secar, levemente, com jato de ar por } 5 \text { segundos; } \\
\text { 4- Aplicar uma camada do primer; } \\
\text { 5- Secar, gentilmente, durante } 5 \text { segundos; } \\
\text { 6- Aplicar camada do adesivo; } \\
\text { 7- } \quad \text { Fotoativar por } 10 \text { segundos; } \\
\text { 8- } \quad \text { Proceder com a restauração. }\end{array}$ \\
\hline $\begin{array}{c}\text { Clearfil }^{\mathrm{TM}} \text { SE Bond } \\
\text { (SE) }\end{array}$ & $\begin{array}{l}\text { 1- } \\
\text { Aplicar camada de primer sobre a superfície de dentina limpa e seca } \\
\text { 2- } \\
\text { 3- }\end{array}$ \\
\hline
\end{tabular}
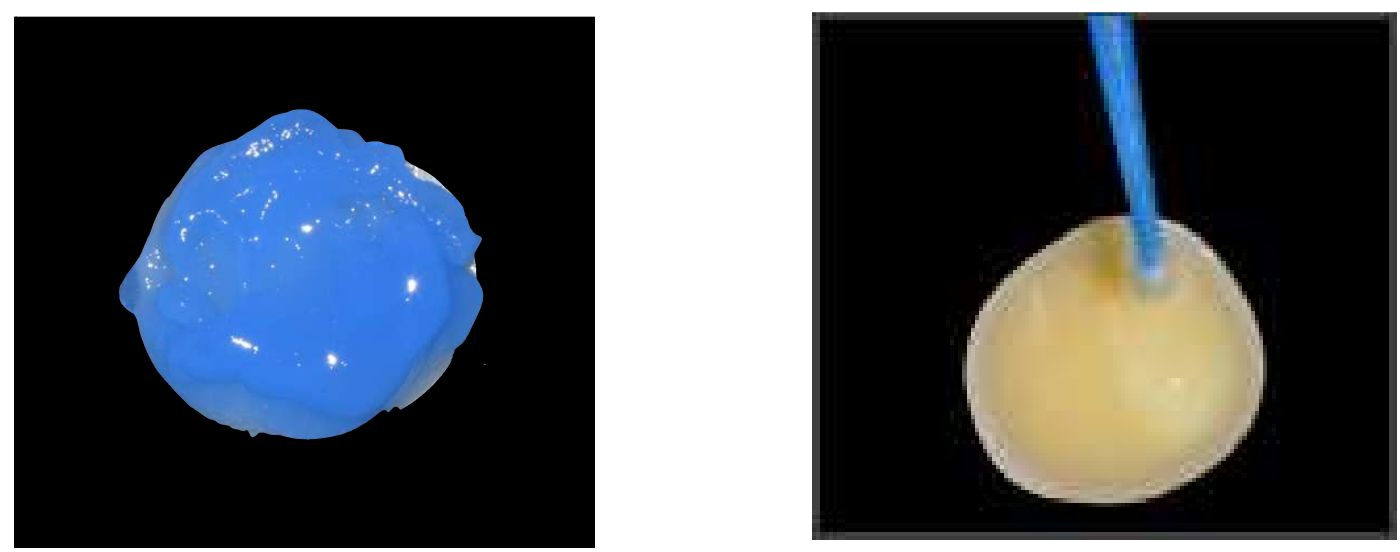
Figura 12: Condicionamento com ácido fosfórico $37 \%$ durante 15 segundos para os grupos MP-C, MP-C1 e MP-C2)

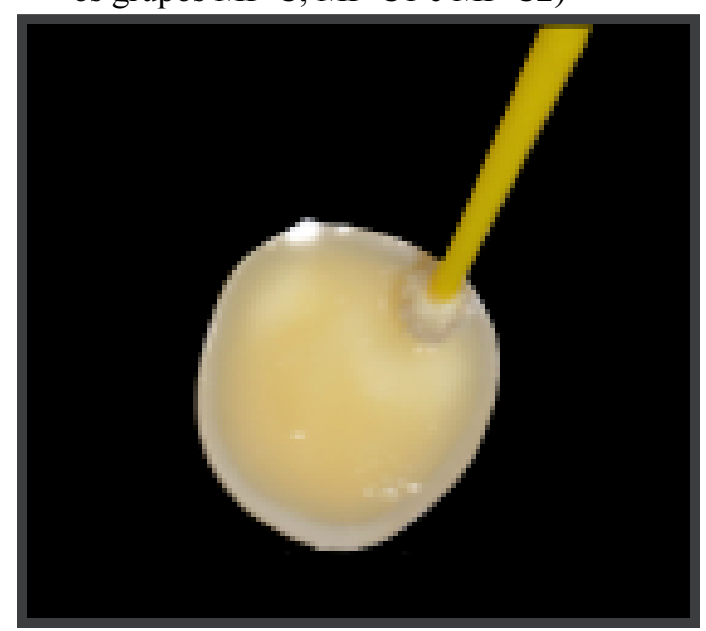

Figura 14: Aplicação do adesivo para os grupos controles
Figura 13: Aplicação do respectivo primer para todos os grupos

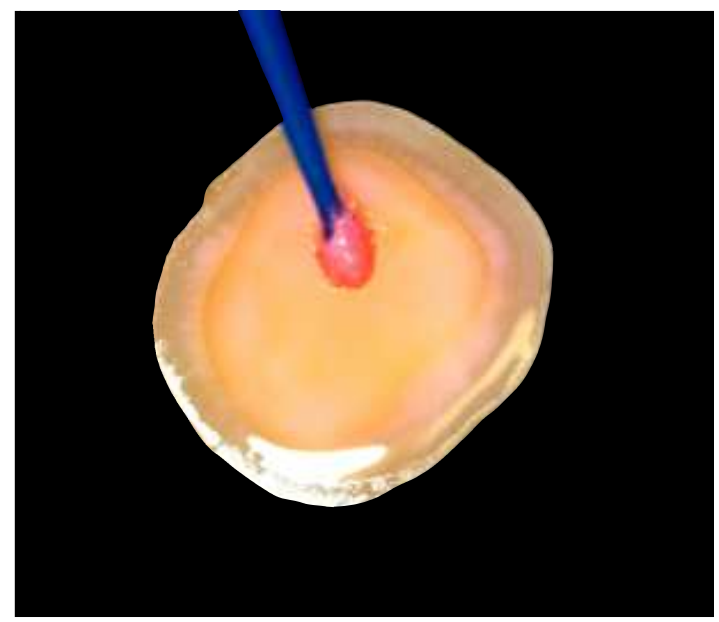

Figura 15: Aplicação do adesivo para os grupos experimentais

A restauração dos espécimes foi realizada com resina composta Filtek ${ }^{\mathrm{TM}} \mathrm{Z} 250(3 \mathrm{M}$ ESPE, St. Paul, MN, EUA), cor A2, utilizando-se a técnica incremental pela deposição consecutiva de três incrementos de $1,5 \mathrm{~mm}$, obtendo-se uma coroa de 4,5mm (Figuras 16 e 17). Cada incremento foi fotoativado por 20 segundos com o mesmo aparelho fotoativador LED, Radii-cal 2 (SDI, Victoria, Bayswater, Austrália) de intensidade de $1.000 \mathrm{~mW} / \mathrm{cm}^{2}$. Após o procedimento restaurador, os dentes foram imersos em água deionizada e mantidos em estufa (Estufa 502, Fanem, São Paulo, SP, Brasil) à temperatura de $37^{\circ} \mathrm{C}$ por 24 horas.

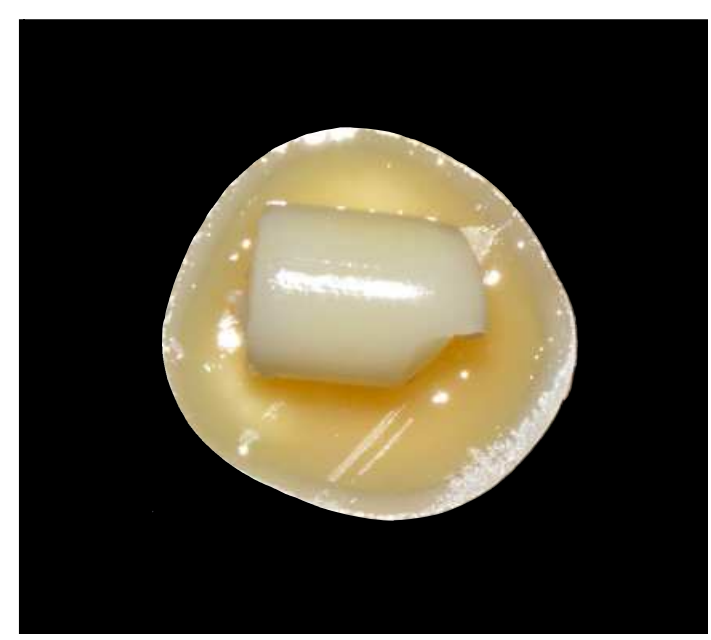

Figura 16: Aplicação de incrementos de resina

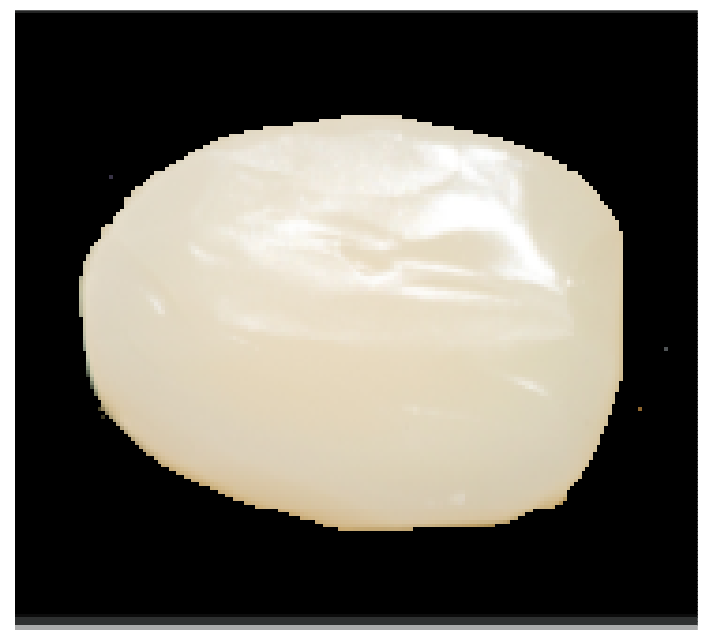

Figura 17: Restauração finalizada apresentado $4,5 \mathrm{~mm}$ de altura 
Após 24 horas do procedimento restaurador, os espécimes foram removidos da estufa e secos. Cada espécime foi fixado com cera pegajosa em dispositivo cilíndrico metálico de base plana, adaptado à mesma màquina de corte utilizada no início da pesquisa, para ser seccionado com disco diamantado (Extec Dia. Wafer blade 5"x.015x1/2, cód 12240 Extec Corp, Einfeld, CT, EUA) em baixa velocidade e sob refrigeração com água. Primeiramente, o seccionamento por desgaste ocorreu no sentido mésio-distal da coroa, gerando fatias de espessura média de $0,8 \mathrm{~mm}$, as quais permaneceram presas na base do dispositivo pela ação retentiva da cera. Em sequência, girando-se a base metálica em $90^{\circ}$, fatias semelhantes foram obtidas no sentido vestíbulo-lingual/palatino do mesmo dente, obtendo-se, assim, espécimes em forma de palito com um área transversal de aproximadamente $0,64 \mathrm{~mm}^{2}$ (Figuras 18 e 19).

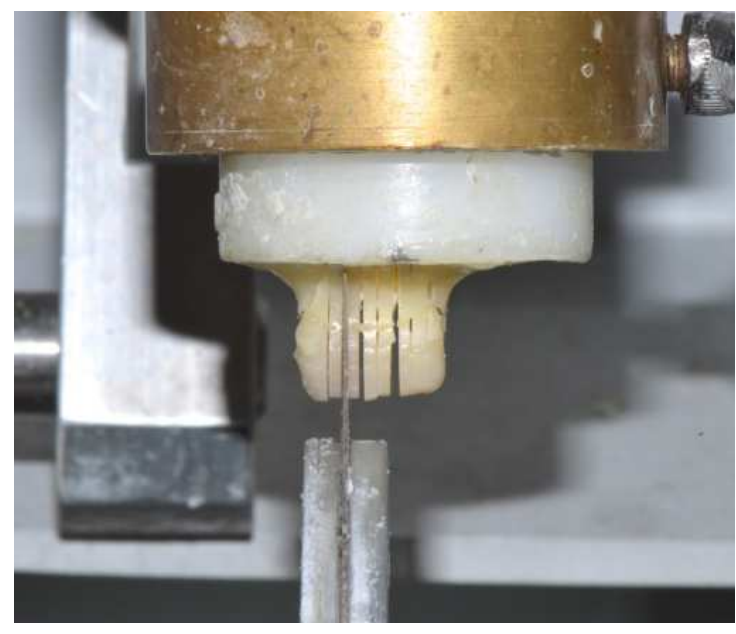

Figura 18: Secção do conjunto dente-restauração

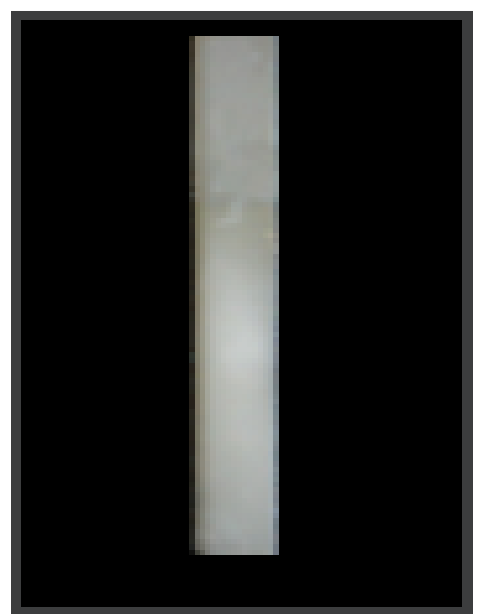

Figura 19: Obtenção de palito com de $0,8 \mathrm{~mm}$ X $0,8 \mathrm{~mm}$ de dimensões

Foram obtidos, em média, nove palitos por espécime, sendo cada terço destes submetidos ao teste de microtração após 7 dias, teste de microtração após 6 meses e o restante armazenado para que futuros testes os avaliem após 1 ano. Até o momento da realização do teste, os palitos foram armazenados em saliva artificial dentro da estufa (Estufa 502, Fanem, São Paulo, SP, Brasil), de acordo com o período de avaliação de cada grupo (MP-C, MP-C1, MP-C2, SE-C, SE-C1 e SE-C2), sendo realizada semanalmente a renovação da saliva. 


\subsection{TESTES DE MICROTRAÇÃO}

Após o período de armazenamento, os palitos foram fixados, individualmente, ao dispositivo de microtração similar ao de Bencor multi $\mathrm{T}$ adaptado à máquina de ensaios universal Instron (Modelo 3342, Instron Corp., Canton, MA, EUA). Para tal, foi empregado um adesivo à base de cianocrilato (Loctite Super Bonder gel control, Henkel Ltda, São Paulo, SP, Brasil) em ambas as extremidades de cada corpo de prova. Os espécimes foram testados sob força de tração, perpendicular à interface de união, utilizando-se uma célula de carga de $500 \mathrm{~N}$ e velocidade de $0,5 \mathrm{~mm} / \mathrm{min}$ até a ruptura do palito (Figura 20). Em seguida à fratura, o espécime foi removido do dispositivo de ensaio com uma lâmina de bisturi $\mathrm{n}^{\circ} 11$. A área transversal de união correspondente à fratura foi medida utilizando paquímetro digital (Messen Sensor Technology Co, Guangdong, China).

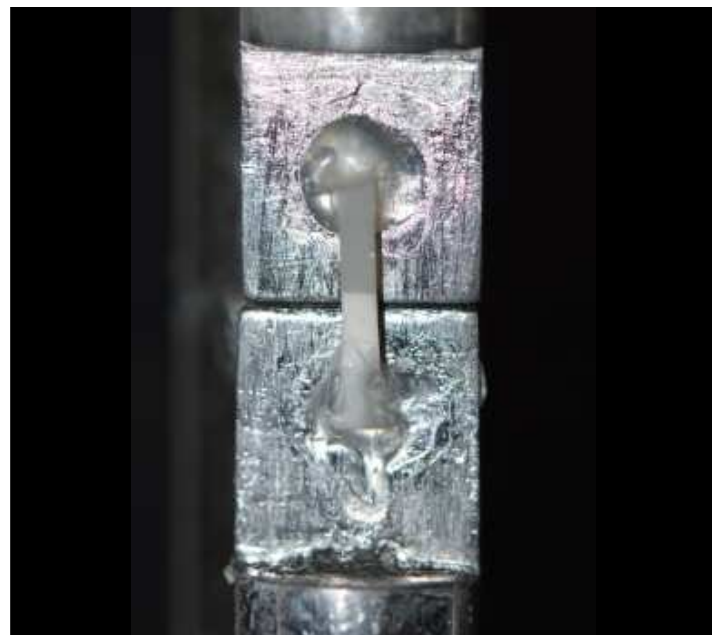

Figura 20: Palito fixado pelas extremidades com adesivo à base de cianocrilato ao dispositivo tipo Bencor

A força necessária para provocar a ruptura dos espécimes foi obtida pela razão entre a carga (Kgf) no momento da fratura e a área de secção transversal do espécime em $\mathrm{mm}^{2}$. Em seguida, os valores foram convertidos em $\mathrm{MPa}$.

As superfícies fraturadas de ambos os segmentos de cada palito foram analisadas com o auxílio de estereomicroscópio digital (200x DINO-LITEplus digital microscope, AnMo Eletronics Corporation, Hsinchu, China - Figura 21), para determinação do tipo de fratura com obtenção de padrão de imagens bem detalhadas. As fraturas foram classificadas em: tipo adesiva (Ta) quando a fratura ocorreu na interface dentina/material restaurador; tipo coesiva 
em dentina (Tcd) quando a fratura ocorreu em substrato dentário (dentina); tipo coesiva em resina composta (Tcr) quando a fratura ocorreu no material restaurador (resina composta); e tipo mista (Tm) quando houve uma combinação de fratura adesiva e coesiva.

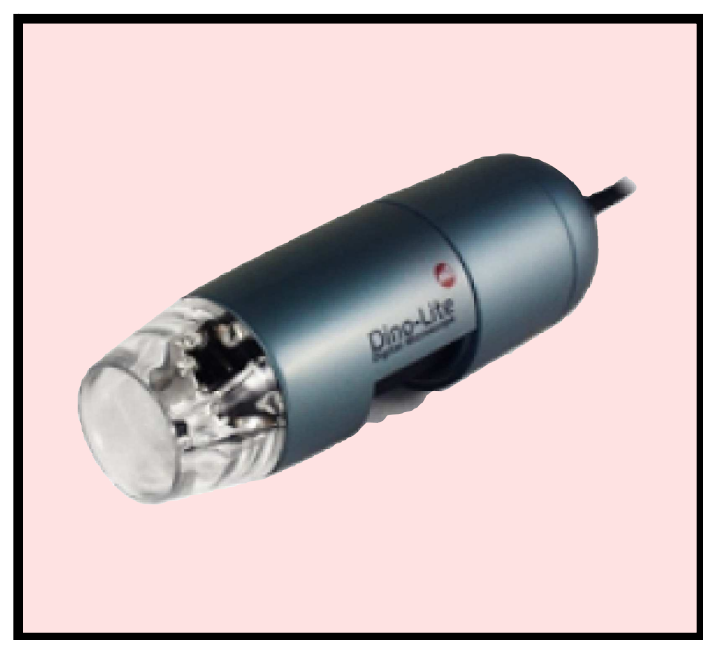

Figura 21: Estereomicroscópio digital utilizado (DINO-LITEplus digital microscope)

\subsection{PREPARO DOS ESPÉCIMES PARA TESTE DE MICRODUREZA DE SUPERFÍCIE}

Foram selecionados trinta e seis dentes para a realização do teste de microdureza de superfície dos sistemas adesivos utilizados na pesquisa. Segmentos de coroa com $3 \mathrm{~mm}$ de altura foram confeccionados, utilizando-se a mesma máquina de corte utilizada no início da pesquisa, com disco diamantado (Extec Corp - 102mm X 0,3mm X 12,7mm, Enfield, CT, EUA) em baixa velocidade e sob refrigeração com água, a fim de se remover o esmalte da face oclusal e expor a superfície de dentina necessária para a leitura de microdureza de superfície. Em sequência, as superfícies dentinárias foram submetidas à ação de desgaste em uma politriz metalográfica (Aropol 2V, Arotec S.A. Industria e Comércio - Cotia, SP, Brasil), de modo que a face de dentina exposta estivesse em contato com a lixa e paralela a mesma. Com a finalidade de obter a planificação final da superfície de dentina, bem como simular a formação de smear layer, foi utilizada lixa d'água com granulação 600 (Carbimet Paper Discs, 30-5108-320, Buehler, Lake Bluff, IL, EUA) durante 30 segundos. Os segmentos de coroa foram fixados em bases de acrílico com o auxílio de cera pegajosa, de maneira que, a superfície dentinária estivesse perpendicular à superfície da base para que não houvesse interferência durante a leitura da microdureza de superfície (Figura 22). 


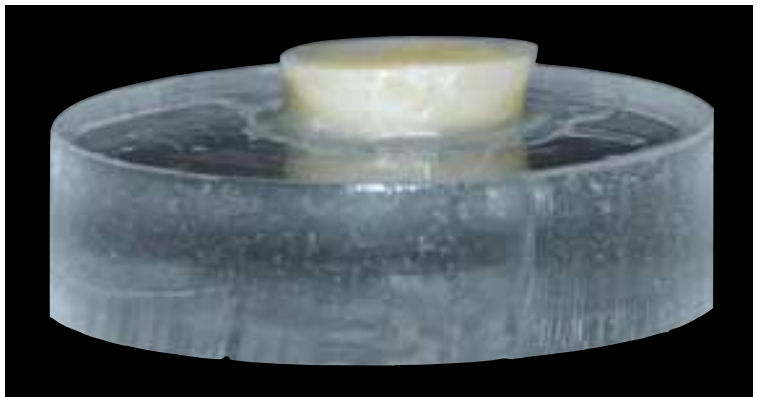

Figura 22: Segmento de coroa (3mm de altura) fixado em base de acrílico

Os sistemas adesivos MP e SE, nos grupos controle e nos respectivos grupos experimentais (Quadro 3), foram aplicados em seis espécimes cada um, sobre superfícies de dentina exposta igualmente tratadas de acordo com a descrição no item 4.5.3 (Figuras 12-15). Após a polimerização dos sistemas adesivos testados, os espécimes foram mantidos secos em estufa (Estufa 502, Fanem, São Paulo, SP, Brasil) à temperatura de $37^{\circ} \mathrm{C}$ por um período de 48 horas.

\subsection{TESTE DE MICRODUREZA DE SUPERFÍCIE}

A avaliação da microdureza Knoop dos sistemas adesivos avaliados foi realizada utilizando-se o microdurômetro Shimadzu HMV-2 (Shimadzu Coporation, Kyoto, Japão), acoplado a um software para análise das imagens, Can-Win (NewAge Industrie, USA Figura 23).

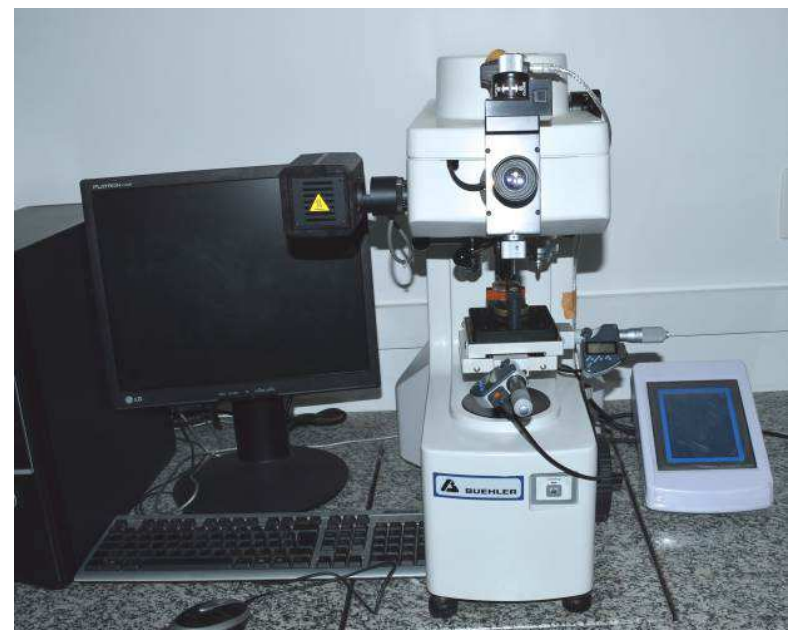

Figura 23: Microdurômetro 
Foram feitas cinco indentações nos espécimes, dispostas da seguinte forma: inicialmente uma marcação na região central da superfície do material; as demais marcações foram obtidas direcionadas para as quatro extremidades do espécime, com uma distância de aproximadamente $200 \mu \mathrm{m}$ do centro. Utilizou-se uma ponta penetradora diamantada piramidal, tipo Knoop e lente de aumento de 10x, sendo a carga estática de $25 \mathrm{gF}$ aplicada por 10 segundos. As medições foram estabelecidas por meio de duas marcas pontilhadas que se sobrepõe aos vértices agudos do losango determinando o comprimento da diagonal maior. $\mathrm{O}$ valor de microdureza de superfície foi obtido por meio de cálculos automáticos feitos pelo software. Após a obtenção das cinco impressões, foi realizada uma média com os valores e determinado o número resultante da microdureza Knoop para cada espécime.

\subsection{ANÁLISE ESTATÍSTICA}

Os resultados de resistência de união à dentina e microdureza de superfície foram analisados pelo teste de análise de variância (ANOVA 2 critérios) e pelo teste Bonferroni para comparações múltiplas, sempre adotando o nível de significância de 5\%. Para a comparação de resistência de união em relação ao tempo, foi utilizado o teste t-pareado, também com nível de significância de $5 \%$. 



\section{RESULTADOS}

\subsection{RESISTÊNCIA DE UNIÃO}

Os valores de média da resistência de união e do desvio padrão estão apresentados na Tabela 1. Para a comparação dos valores de 7 dias, os fatores sistema adesivo $(p=0,0003)$ e a concentração adicionada de rodamina $B(p<0,0001)$ foram significantes. Não houve interação entre esses dois fatores $(p=0,477)$. Para a comparação dos valores de 6 meses, apenas o fator concentração adicionada de rodamina $B$ foi significante $(p=0,036)$, sendo o fator adesivo $(p=0,909)$ e a interação $(p=0,142)$ estatisticamente não significantes.

$\mathrm{Na}$ análise comparativa da resistência de união de cada um dos sistemas adesivos nos dois tempos (7 dias x 6 meses), o fator tempo foi significante, sendo reduzido após o envelhecimento. Os respectivos valores de $\mathrm{p}$ para cada sistema adesivo foram MP-C $(p<0,0001)$, MP-C1 $(p=0,0056)$, MP-C2 $(P=0,0010)$, SE-C $(p<0,0001)$, SE-C1 $(p=0,0003)$ e SE-C2 $(p=0,003)$.

Tabela 1: Valores de média (MPa) e desvio padrão de resistência de união dos grupos testados nos tempos de 7 dias e 6 meses

\begin{tabular}{|c|c|c|c|c|}
\hline ADESIVO & MP - 7 DIAS & MP - 6 MESES & SE - 7 DIAS & SE - 6 MESES \\
\hline C (controle) & $41,95(2,38) \mathrm{Aa}^{*}$ & $22,76(3,66) \mathrm{Aa}+$ & $46,07(1,43) \mathrm{Aa}^{*}$ & $19,07(6,75) \mathrm{Aa}+$ \\
\hline $\mathrm{C} 1(0,02 \mathrm{mg} / \mathrm{mL})$ & $28,02(5,12) \mathrm{Ab}^{*}$ & $17,93(5,70) \mathrm{Aab}+$ & $37,49(13,31) \mathrm{Bb}^{*}$ & $18,54(6,71) \mathrm{Aa}+$ \\
\hline $\mathrm{C} 2(0,10 \mathrm{mg} / \mathrm{mL})$ & $26,28(5,55) \mathrm{Ab}^{*}$ & $14,30(5,68) \mathrm{Ab}+$ & $34,16(7,71) \mathrm{Bb}^{*}$ & $17,89(4,87) \mathrm{Aa}+$ \\
\hline
\end{tabular}

$\mathrm{N}=10$

Letras maiúsculas diferentes indicam diferenças significantes entre colunas de uma mesma linha $(p<0,05)$, comparando diferentes sistemas adesivos, sempre no mesmo tempo.

Letras minúsculas diferentes indicam diferenças significantes entre linhas de uma mesma coluna $(p<0,05)$, comparando as diferentes concentrações de rodamina B para um mesmo sistema adesivo.

Símbolos diferentes indicam diferenças significantes entre colunas de uma mesma linha $(\mathrm{p}<0,05)$, comparando o mesmo sistema adesivo em diferentes tempos. 
Na comparação da resistência de união entre diferentes sistemas adesivos, no tempo de 7 dias, verificam-se diferenças estatisticamente significantes nos grupos MP-C1 x SE-C1 e MP-C2 x SE-C2. Na comparação de cada sistema adesivo, verifica-se diferença estatisticamente significante entre os grupos controles MP e SE em relação a seus respectivos grupos experimentais, modificados pelas duas concentrações de rodamina B adicionada.

Após 6 meses de armazenamento, ao analisar diferentes sistemas adesivos, observouse uma redução significativa dos valores de RU para todas as situações. Por outro lado, quando os valores de resistência de união entre diferentes grupos de um mesmo sistema adesivo são comparados, verifica-se diferença estatisticamente significante tão somente entre os grupos MP-C x MP-C2.

Considerando-se o fator tempo, encontrou-se diferença estatisticamente significante para os valores de resistência de união para todos os grupos testados entre o tempo 7 dias x 6 meses.

As análises de fratura relativas ao tempo de 7 dias e de 6 meses estão apresentados na Tabela 2 e 3.

Tabela 2: Distribuição das fraturas em porcentagem de acordo com a concentração de rodamina $B$ no tempo de 7 dias

\begin{tabular}{c|c|c|c|c|c|c|c|c}
\multicolumn{5}{c|}{ ADESIVO } & \multicolumn{5}{c|}{ MP } & \multicolumn{3}{c}{ SE } \\
RODAMINA B & Ta & Tm & Ted & Ter & Ta & Tm & Ted & Ter \\
\hline C ( controle) & 67,85 & 28,58 & 0 & 3,57 & 67,85 & 32,15 & 0 & 0 \\
\hline $\mathbf{C 1}(\mathbf{0 , 0 2} \mathbf{~ m g / m L )}$ & 59,00 & 41,00 & 0 & 0 & 60,71 & 35,71 & 3,58 & 0 \\
\hline $\mathbf{C 2}(\mathbf{0 , 1 0} \mathbf{~ m g / m L )}$ & 52,00 & 45,00 & 3,00 & 0 & 62,08 & 31,02 & 3,45 & 3.45 \\
\hline
\end{tabular}

*Fratura do tipo adesiva (Ta), mista (Tm), coesiva em dentina (Tcd), coesiva em resina (Tcr) 
Tabela 3: Distribuição das fraturas em porcentagem de acordo com a concentração de rodamina B no tempo de 6 meses

\begin{tabular}{c|c|c|c|c|c|c|c|c}
\multicolumn{5}{c|}{ ADESIVO } & \multicolumn{5}{c|}{ MP } & \multicolumn{3}{c}{ SE } \\
RODAMINA B & Ta & Tm & Ted & Ter & Ta & Tm & Ted & Ter \\
\hline C ( controle) & 73,00 & 26,67 & 0 & 3,33 & 66,67 & 33,33 & 0 & 0 \\
\hline C1 (0,02 mg/mL) & 62.08 & 37,92 & 0 & 0 & 64,28 & 35,71 & 0 & 0 \\
\hline C2 (0,10 mg/mL) & 60,71 & 39,29 & 0 & 0 & 66,67 & 29,63 & 3,7 & 0 \\
\hline
\end{tabular}

*Fratura do tipo adesiva (Ta), mista (Tm), coesiva em dentina (Tcd), coesiva em resina (Tcr)

$\mathrm{Na}$ análise das tabelas é possível verificar que para todos os grupos, nos tempos de 7 dias e 6 meses, houve predominância de fraturas adesivas entre o adesivo e a dentina, seguido pelas fraturas mistas.

\subsection{MICRODUREZA DE SUPERFÍCIE}

Os valores de média da microdureza de superfície e do desvio padrão estão apresentados na Tabela 4. Para a comparação dos valores, apenas o fator sistema adesivo foi significante $(\mathrm{p}<0,0001)$, o que não foi para o fator concentração de rodamina $\mathrm{B}$ adicionada $(p=0,2116)$. Nota-se que não houve interação entre os fatores sistema adesivo e concentração adicionada de rodamina $\mathrm{B}(\mathrm{p}=0,7388)$.

Tabela 4: Valores de média e desvio padrão da microdureza de superfície dos grupos

\begin{tabular}{c|c|c} 
ADESIVO & MP & SE \\
RODAMINA B & & \\
\hline $\mathbf{C}-\mathbf{C o n t r o l e ~}$ & $8,97(3,85) \mathrm{Aa}$ & $4,71(4,42) \mathrm{Ba}$ \\
\hline $\mathbf{C} 1-\mathbf{0 , 0 2} \mathbf{~ m g / m L}$ & $7,33(0,99) \mathrm{Aa}$ & $4,42(0,56) \mathrm{Aa}$ \\
\hline $\mathbf{C} 2-\mathbf{0 , 1 0} \mathbf{~ m g / m L}$ & $7,17(2,45) \mathrm{Aa}$ & $3,27(0,30) \mathrm{Ba}$ \\
\hline
\end{tabular}

$\mathrm{N}=6$

Letras maiúsculas diferentes indicam diferenças significantes entre colunas de uma mesma linha $(p<0,05)$, comparando diferentes sistemas adesivos, sempre na mesma concentração

Letras minúsculas diferentes indicam diferenças significantes entre linhas de uma mesma coluna $(p<0,05)$, comparando as diferentes concentrações de rodamina B para um mesmo sistema adesivo 
Quando valores de microdureza de superfície entre os diferentes grupos de um mesmo sistema adesivo são comparados, verifica-se a ausência de diferenças estatisticamente significantes.

$\mathrm{Na}$ comparação entre os sistemas adesivos MP e SE, na mesma concentração adicionada de rodamina $\mathrm{B}$, houve diferença estatisticamente significante entre os grupos controle $(p<0,01)$ e na concentração $0,10 \mathrm{mg} / \mathrm{mL}(\mathrm{p}<0,05)$. 


\section{DISCUSSÃO}

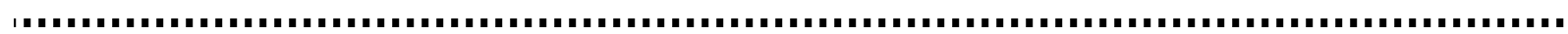





\section{DISCUSSÃO}

Com base nos resultados obtidos no estudo, as 3 hipóteses nulas foras rejeitadas. Para uma melhor interpretação, discutiremos a partir da relevância do uso do agente fluorescente rodamina $\mathrm{B}$ associado à visualização da interface de união.

A análise micromorfológica e a visualização da integridade da interface de união pela MCVL podem ser consideravelmente aperfeiçoadas por meio da incorporação de corantes fluorescentes nos sistemas adesivos (WATSON, 1997; D’ALPINO et al., 2006b). Para que essa adição de agentes fluorescentes seja efetiva, torna-se fundamental que haja uma estratégia sistemática para que se preservem as características iniciais das propriedades esperadas dos diferentes sistemas. No presente estudo, a rodamina B foi selecionada como o marcador fluorescente a ser analisado por ser aquele mais comumente utilizado na microscopia de fluorescência (PIOCH et al., 1997; DIASPRO et al., 2001) e, também, usado na Odontologia para analisar as características de adesão nos tecidos duros dentários e a interação entre os materiais usados na prática clínica (DIASPRO et al., 2001; ARRAIS et al., 2009; FRANCISCONI et al., 2009; SAMPAIO et al., 2011; AGUIAR et al., 2012). Bim Junior (2013) demonstrou a possibilidade de incorporar rodamina B nas concentrações de $0,02 \mathrm{mg} / \mathrm{mL}$ e $0,10 \mathrm{mg} / \mathrm{mL}$ nos sistemas adesivos por meio de dissolução em etanol. Essa estratégia permitiu a visualização adequada na MCVL e a precisão no seu preparo. Sendo assim, esse estudo investigou o uso de rodamina B nas mesmas concentrações em propriedades físico-mecânicas relevantes para a análise do comportamento de sistemas adesivos.

$\mathrm{Na}$ literatura científica não há evidências da quantidade de rodamina $\mathrm{B}$, e de outros marcadores fluorescentes, necessária e suficiente para a visualização da interface de sistemas adesivos marcados. Muitos trabalhos publicados não relatam a concentração dos marcadores fluorescentes utilizados e a sua técnica de incorporação nos sistemas adesivos. Em poucos trabalhos, consta apenas que o marcador foi adicionado diretamente no interior do frasco de adesivo fornecido pelo fabricante (D’ALPINO et al., 2006a; ARRAIS et al., 2009). Esse procedimento de adição não tem sido realizado com rigor e de forma precisa, devido à incerteza de que o conteúdo líquido do frasco seja, exatamente, igual ao informado no rótulo do produto pelo fabricante. Além disso, o pequeno volume em que os sistemas adesivos são comercializados impossibilita a pesagem de concentrações pequenas do marcador fluorescente nas soluções. Esses fatores podem ter contribuído para que, na maioria dos 
estudos publicados, a concentração de marcador fluorescente nos sistemas adesivos tenha sido maior do que o necessário para a adequada visualização das estruturas na MVCL.

Bim Júnior (2013) analisou por meio da MCVL o marcador fluorescente rodamina B dissolvido separadamente em primers ou em adesivos. Por meio do referido procedimento foi possível constatar como a marcação distinta desses componentes influenciou na análise morfológica da interface de união. Quando a rodamina B foi adicionada somente nos primers, houve uma maior visualização dos tags de resina, ao passo que a camada híbrida apresentou menor saturação e contraste. Já nos casos em que a rodamina B foi adicionada apenas nos adesivos, ocasionou uma visualização mais homogênea da camada de resina composta impregnada por rodamina $\mathrm{B}$, da camada subjacente de adesivo marcado, da camada hibrida e do tags, comprovando que a adição desse marcador fluorescente nos adesivos forneceu melhores resultados de visualização das estruturas observadas microscopicamente.

No presente estudo, a adição de rodamina B aos sistemas adesivos foi feita somente nos adesivos, baseada nos resultados da pesquisa realizada anteriormente. Assim, os sistemas adesivos MP e SE foram modificados com a rodamina $B$ em duas concentrações $(0,02 \mathrm{mg} / \mathrm{mL}$ e $0,10 \mathrm{mg} / \mathrm{mL}$ ). Como foi empregado um volume muito pequeno (microlitros) de resina fluida, houve a necessidade de se adotar a técnica de proporcionamento e dissolução em etanol para a incorporação da rodamina B nos sistemas adesivos. Com essa técnica, o volume das alíquotas pôde ser adquirido facilmente, com o auxílio de micropipeta, e transferido para recipiente apropriado para a mistura com os sistemas adesivos (BIM JÚNIOR, 2013).

$\mathrm{Na}$ análise de resistência de união dos dois sistemas adesivos testados, a rodamina $\mathrm{B}$ reduziu significantemente ambos os sistemas no tempo de 7 dias. Para interpretar esse desempenho, deve-se considerar que a rodamina B não apresenta uma reação química com os componentes de nenhum desses sistemas adesivos, permanecendo presa à rede polimérica após a polimerização. Essa molécula livre pode apresentar movimentação na cadeia e, portanto, interferir, também diminuindo a conversão de monômeros, o que pode prejudicar as propriedades mecânicas da camada híbrida (WATSON, 1997; D’ALPINO et al., 2006a, ARAÚJO et al., 2013). Os resultados desse trabalho corroboram com a dinâmica apresentada, demonstrando que de fato há a interferência na propriedade de adesão ao substrato dentário para ambos os sistemas adesivos no tempo de 7 dias. Esses dados reforçam o cuidado necessário na associação de sistemas adesivos aos marcadores fluorescentes, evitando o seu uso arbitrário. 
Ao compararmos a resistência de união entre MP x SE no tempo de 7 dias, ainda, observamos que apenas nos grupos controle (sem rodamina), os sistemas apresentaram valores equivalentes. $\mathrm{Na}$ presença de rodamina $\mathrm{B}$, o sistema adesivo $\mathrm{SE}$ apresentou valores superiores aos do sistema MP, atestando a influência do fator adesivo no comportamento diferenciado entre os agentes testados.

Analisando cada sistema adesivo no tempo de 6 meses, apenas no sistema adesivo MP houve uma diminuição significante de resistência de união no grupo modificado com rodamina $\mathrm{B}$ com a concentração de $0,10 \mathrm{mg} / \mathrm{mL}$. Para o sistema adesivo $\mathrm{SE}$, não houve diferença significativa entre o controle e os grupos modificados com rodamina B no tempo de 6 meses. Na análise comparativa dos diferentes sistemas adesivos, os valores de resistência de união foram similares.

As características químicas dos sistemas adesivos ( $\mathrm{pH}$, tipo e quantidade de solvente, monômeros, presença de partículas inorgânicas) influenciam a adesão à superfície dentinária e podem explicar os resultados encontrados nesse estudo.

A aplicação do sistema adesivo SE é feita em dois passos, na qual o primer promove a dissolução da smear layer e a desmineralização da superfície dentinária, com difusão simultânea dos monômeros hidrofílicos na extensão desmineralizada. Assim, há a expectativa do preenchimento da região desmineralizada pelo primer ácido e pelos monômeros hidrofóbicos (adesivo) de forma mais completa e homogênea, obtendo-se maior uniformidade da camada híbrida (TAY et al., 2000). O SE possui na sua composição água como solvente e um agente de molhamento (HEMA - 2-hidroxietil Metacrilato), considerados facilitadores da penetração do adesivo. Esse sistema adesivo atua com um monômero bifuncional 10-MDP (10-metacriloiloxidecil di-hidrogênio fosfato). Os monômeros ácidos apresentam baixo peso molecular, possibilitando melhor difusão e maior penetrabilidade desses monômeros para a formação da interface adesiva (BRAZ et al., 2011). Os resultados podem sugerir que características da natureza do SE sejam menos suscetíveis ao uso associado da rodamina B do que o sistema MP. Parte desse desempenho pode ser devido à presença e ao mecanismo do MDP, uma vez que esse monômero apresenta ligações químicas com o substrato que podem não ter sido influenciadas pela relação com a luz que esse agente pode exercer.

O monômero bifuncional 10-MDP apresenta alto potencial para adesão química à hidroxiapatita, formando sal de cálcio altamente insolúvel (FUKEGAWA et al., 2006; 
YOSHIHARA et al., 2010). Quanto menos solúvel o sal de cálcio de uma molécula ácida, mais intensa e estável é a adesão molecular ao substrato de base-hidroxiapatita (VARGAS; COBB; ARMSTRONG, 1997). Ademais, o SE possui valor de $\mathrm{pH}$ aproximado de 3,5, o que provoca um condicionamento leve da superfície dentinária, preservando a hidroxiapatita da camada híbrida, que servirá como receptora para adesão química adicional com o 10-MDP (BRAZ et al., 2011). Por isso, o modo de aplicação e as características químicas discutidas acima podem explicar os resultados encontrados.

Por outro lado, o sistema adesivo MP é um sistema convencional de três passos, cujo agente adesivo contém, primordialmente, o monômero hidrofóbico Bis-GMA (Bisfenol-A glicidil metacrilato). Esse monômero apresenta alta massa molar e alta viscosidade, o que confere ao adesivo MP uma característica mais viscosa, podendo influenciar na penetração do adesivo e, consequentemente, na resistência de união. Para essa adesão ao substrato, o mecanismo requer a desmineralização da dentina pela ação do ácido fosfórico em concentrações que variam entre 30 e $40 \%$, aplicados por 15 segundos. Em seguida, faz-se a aplicação de um monômero hidrofílico (primer), que prepara o substrato para a aplicação do adesivo propriamente dito (monômero hidrofóbico). Após a desmineralização, o controle da umidade dentinária representa uma dificuldade dessa técnica, pois tanto a remoção em excesso da água, que pode colabar as fibrilas de colágeno expostas pelo condicionamento, quanto o excesso deixado, podem comprometer a infiltração do sistema adesivo e, em função disso, também a sua eficácia (REIS et al., 2006).

Na comparação de cada sistema adesivo isoladamente, entre os tempos de 7 dias e de 6 meses nota-se que os dois sistemas reduziram os valores significativamente quanto à resistência de união. Essa análise é importante, pois nos remete ao comportamento esperado de acordo com a natureza resinosa desses materiais ao longo do tempo em ambiente aquoso. Os sistemas adesivos, mesmo não simplificados, quando expostos ao meio aquoso por um tempo de armazenagem, sofrem um processo de hidrólise, quebrando gradativamente as ligações covalentes entre os polímeros, causando a perda de massa de resina no interior da camada híbrida, o que reduz a resistência de união (BRESCHI et al., 2008).

A análise dos tipos de fraturas com estereomicroscópio digital revelou que houve predominância das falhas adesivas em todos os grupos e nos dois períodos de tempo. Segundo Sano et al. (1994), as maiores forças de tensão ocorrem na periferia da interface de união 
devido à pequena área de superfície dos espécimes, o que provoca o aumento da probabilidade de defeitos que levam à propagação de falhas adesivas.

Além da análise da resistência de união por microtração, foi realizado o teste de microdureza de superfície. Essa verificação mede a resistência de um material à penetração de um dispositivo colocado sobre a superfície do mesmo por um determinado período de tempo, de modo que o dispositivo deixe uma impressão (YEARN, 1985). Uma das razões de se utilizar essa verificação nessa fase encontra-se no fato de que ela pode fornecer uma análise da qualidade de polimerização desse material. O grau de conversão pode ser determinado por diferentes metodologias, envolvendo métodos diretos ou indiretos. A microdureza de superfície tem sido um dos métodos indiretos mais empregados para analisar o grau de conversão, haja vista ser simples e barata.

Diversos estudos realizados empregaram os ensaios de microdureza Vickers, Knoop, Tukon e Wallace, com as cargas variando de 10 a 200 gramas e os tempos de 5 a 60 segundos (RUEGGEBERG; GRAIG, 1988; HOTTA; HIRUKAWA, 1994; LI; BEETZEN; SWIFT JR et al., 1995; YAP et al., 2001, BASTING; SERRA; RODRIGUES JR, 2002; ELLAKURIA et al., 2003; YLI-URPO et al., 2005; SILVA et al., 2012). Nesse estudo a microdureza Knoop foi utilizada por possuir um penetrador de diamante com forma piramidal de base alongada, o qual permite a utilização em regiões mais finas, já que para uma mesma carga, a profundidade da impressão Knoop é menor do que a metade da profundidade obtida com a impressão Vickers. Destaca-se que a carga e o tempo devem ser baseados no material a ser testado. Por isso, a carga de $25 \mathrm{gf}$ foi utilizada com o próposito de obter impressões regulares, sem deformações e de tamanhos compatíveis com o visor do computador, e o tempo foi de 10 segundos.

Alguns estudos têm mostrado uma correlação entre a microdureza e o grau de conversão (FERRACANE, 1985; BOUSCHLICER et al., 2004; RODE et al., 2007). Apesar da falta de consenso (CHUNG; GREENER, 1990; DA SILVA; POSKUS; GUIMARÃES, 2008) de como a microdureza pode refletir no grau de ligação cruzada entre as cadeias poliméricas, esse método é utilizado e aceito na literatura. As cadeias longas de polímeros são responsáveis pela formação das ligações cruzadas e pela adequada polimerização do material (grau de polimerização). Logo, o grau de conversão não indica necessariamente uma adequada polimerização, pois há a possibilidade da formação de cadeias poliméricas curtas. 
A densidade e a distribuição das ligações cruzadas entre as cadeias poliméricas (AJITHKUMAR; PATEL; KANSARA, 2000) desempenham um relevante papel na coesão final do polímero (SIDERIDOU; TSERKI; PAPANASTASIOU, 2003). Redes poliméricas homogêneas com elevado nível de ligações cruzadas favorecem as propriedades mecânicas do material (ELLIOTT; LOVELL; BOWMAN, 2001). Por outro lado, uma restauração subpolimerizada pode apresentar menor resistência à degradação pelo esforço mastigatório, fraturas, irritação pulpar, descoloração, perda de massa com consequente reinstalação de cárie (HANSE; ASMUSSEN, 1993; MIYASAKI et al., 1996).

$\mathrm{O}$ presente trabalho não visou necessariamente correlacionar $\mathrm{o}$ emprego da microdureza de superfície ao grau de conversão, e sim comparar os grupos controle e experimentais, para saber se a rodamina $\mathrm{B}$ exerceria alguma modificação na qualidade polimérica.

Ao analisar os resultados de microdureza de superfície, houve diferença significante entre os dois sistemas adesivos testados, o que novamente remete à natureza dos seus componentes, como já citado. A rodamina $\mathrm{B}$, independente da sua concentração, não interferiu em nenhum sistema adesivo quanto à microdureza de superfície. Assim, nessa análise, esse fator não será considerado, já que essa adição não representou um problema para a qualidade polimérica na concentração e nas forma inseridas.

Tanto o sistema adesivo MP quanto o SE apresentam o monômero hidrofílico HEMA no agente adesivo propriamente dito, além do BisGMA para o MP e BisGMA associado ao 10-MDP para o SE, conforme já mencionado. Naturezas poliméricas distintas são convertidas de formas diferentes e, por isso, os resultados diferenciados entre os adesivos estão de acordo com a literatura (FARIA-E-SILVA et al., 2010; LOGUERCIO et al., 2014).

Outro aspecto importante a ser considerado nessa análise é o fato de que o sistema adesivo (incluindo o primer) foi aplicado ao substrato para a leitura, diferentemente dos trabalhos que avaliam a microdureza em espécimes isolados dos agentes adesivos propriamente ditos. Desse modo, não é possível ignorar que pode haver o efeito também da interação do primer no adesivo para essa leitura, tendo em vista que a presença de solventes orgânicos residuais pode exercer influência na polimerização subsequente do agente adesivo propriamente dito (CANDENARO et al., 2009; LUQUE-MARTINEZ et al., 2014). 
A presença de água é essencial na composição de sistemas adesivos convencionais e autocondicionantes. Nos adesivos convencionais, a água tem o efeito plastificante nas fibrilas de colágeno e diminui a rigidez da fibrila colapsada, o que se revela importante para a expansão do colágeno na dentina seca (MACIEL et al., 1996). Já nos adesivos autocondicionantes, a presença de água permite a ionização dos monômeros ácidos e a desmineralização dos tecidos dentais duros (TAY; PASHLEY, 2001). Contudo, a evaporação do solvente antes da fotopolimerização do sistema adesivo é um passo importante durante a sua aplicação, pois é capaz de melhorar as propriedades mecânicas e aumentar a resistência de união. A presença de água residual ou de solventes orgânicos pode ser responsável pela formação de áreas com incompleta polimerização dos monômeros (DICKENS; CHO, 2005; FABRE et al., 2007; GARCIA et al., 2010). Jacobsen e Söderholm (1995) avaliaram a adição de quantidades crescentes de água (5-44 vol\%) na formulação de HEMA e Bis-GMA, sendo que essa última foi subsequentemente polimerizada. Foi observado que a adição de apenas 9\% de água reduziu o grau de conversão do sistema adesivo em $20 \%$.

As instruções de uso dos sistemas adesivos chamam a atenção para a aplicação do primer sobre a dentina e, em seguida, para a secagem com jatos de ar. Presumivelmente, jatos de ar são utilizados para diluir a solução, bem como evaporar a água que serve como diluente para o HEMA. Tendo em vista que a água é evaporada da mistura água-HEMA presente no primer, a concentração de HEMA aumenta rapidamente por causa da grande diferença de volatilidade entre os dois líquidos. Essa diferença provoca a diminuição progressiva da pressão de vapor de água, tornando mais difícil a remoção da água residual durante a evaporação. (PASHLEY et al., 1998). Para os adesivos autocondicionantes, o passo de evaporação do solvente é crítico, pois eles contêm alta concentração de solventes (VAN LANDUYT et al., 2007), que pode interferir na polimerização dos monômeros (PASHLEY et al., 2002). Portanto, a remoção do solvente deve ser realizada da forma mais eficiente possível, sempre seguindo as instruções do fabricante de cada sistema adesivo.

Nesse estudo, seguindo as instruções do fabricante, após a aplicação do primer do sistema adesivo MP sobre a dentina, realizou-se a aplicação de leves jatos de ar durante 5 segundos para a evaporação do solvente. No sistema adesivo SE, o fabricante não determina em quantos segundos deve ser feita a evaporação do solvente, apenas recomendando aguardar por 20 segundos após a aplicação do primer e, em seguida, secar a superfície dentinária com leve jato de ar. Essa diferença também pode contribuir para o desempenho diferenciado encontrado. 
Outra hipótese que pode justificar os valores obtidos no teste de microdureza de superfície é a presença de água residual na superfície dentinária dos espécimes do grupo SE. Os sistemas adesivos autocondicionantes foram aplicados sobre a dentina um pouco mais seca (GORDAN et al., 1997). Já os sistemas adesivos convencionais foram aplicados sobre a dentina por meio da técnica úmida, já que se buscava uma adesão satisfatória (GWINNETT, 1992; KANCA, 1992). Por isso, a presença de água residual na superfície dentinária dos espécimes, antes da aplicação do sistema adesivo SE, pode ter tornado a evaporação do solvente com leve jato de ar insatisfatória, formando áreas de incompleta polimerização de monômeros e, consequentemente, reduzindo os valores de microdureza de superfície desse grupo.

Por meio da interpretação dos resultados obtidos, pode-se afirmar que as concentrações de rodamina $B$ de $0,02 \mathrm{mg} / \mathrm{mL}$ e $0,10 \mathrm{mg} / \mathrm{mL}$ são capazes de afetar negativamente os valores de resistência de união dos sistemas adesivos MP e SE, exceto para os grupos SE no tempo de 6 meses. Apesar das duas concentrações testadas terem interferido negativamente nos valores de resistência de união dos sistemas adesivos MP e SE ao longo do tempo, essa redução está mais relacionada à natureza polimérica dos sistemas adesivos do que à presença de rodamina $\mathrm{B}$. $\mathrm{Na}$ análise de microdureza, esse agente fluorescente não prejudicou essa propriedade em nenhum caso.

Demonstra-se importante que pesquisas futuras avaliem a influência da adição de rodamina B nos sistemas adesivos não simplificados em outras propriedades mecânicas. Ademais, estudos posteriores devem comparar diferentes concentrações de rodamina $\mathrm{B}$, de maneira que o uso desse marcador fluorescente associado à MCVL não altere as propriedades mecânicas do material, nem induza a interpretações equivocadas. 



\section{CONCLUSÕES}

Com base nos resultados obtidos, pode-se concluir que:

1. Nos sistemas adesivos MP e SE modificados com rodamina B nas duas concentrações, houve um comportamento negativo da resistência de união, quando comparado aos mesmos sistemas adesivos puros, no mesmo tempo, exceto para os grupos SE no tempo de 6 meses.

2. Para os sistemas adesivos MP e SE, os valores de resistência de união foram reduzidos ao longo do tempo, independente da concentração de rodamina $\mathrm{B}$ adicionada.

3. Os valores de microdureza de superfície foram semelhantes para cada sistema adesivo, independente da concentração de rodamina B adicionada. 




\section{REFERÊNCIAS}

Aboushelib MN. Clinical performance of self-etching adhesives with saliva contamination. J Adhes Dent. 2011;13(5):489-93.

Aguiar TR, Andre CB, Arrais CAG, Bedra-Russo AK, Giannini M. Micromorphology of resin-dentin interfaces using self-adhesive and conventional resin cements: a confocal laser and scanning electron microscope analysis. Int J Adhes Adhes. 2012;38(1):69-74.

Ajithkumar S, Patel NK, Kansara SS. Sorption and diffusion of organic solvents through interpenetrating polymer networks (IPNs) based on polyurethane and unsaturated polyester. Eur Polym J. 2000;36(11):2387-93.

Araújo CTP, Prieto LT, Oliveira DCRS, Coppini EK, Lima AF, Silva WJ, et al. Influence of fluorescent dye on mechanical properties of adhesive systems. Int J Adhes Adhes. 201;47(1):129-33.

Arrais CA, Miyake K, Rueggeberg FA, Pashley DH, Giannini M. Micromorphology of resin/dentin interfaces usin $4^{\text {th }}$ and $5^{\text {th }}$ generation dual-curing adhesive/cement systems: a confocal laser scanning microscope analysis. J Adhes Dent. 2009;11(1):15-26.

Basting RT, Serra MC, Rodrigues Jr AL. In situ microhardness evaluation of glassionomer/composite resin hybrid materials at diferent post-irradiation times. J Oral Rehab. 2002;29(12):1187-93.

Bitter K, Paris S, Mueller J, Neumann K, Klelbassa AM. Correlation of Scanning Electron and Confocal Laser Scanning Microscopic Analyses for Visualization of Dentin/Adhesive Interfaces in the Root Canal. J Adhesi Dent. 2009;11(1):7-14.

Bim Júnior O. Estratégias para adição de Rodamina B em sistemas adesivos [dissertação].Bauru: Faculdade de Odontologia de Bauru, Universidade de São Paulo; 2013.

Bottino MC, Batarseh G, Palasuk J, Alkatheeri MS, Windsor LJ, Platt JA. Nanotube-modified dentin adhesive--physicochemical and dentin bonding characterizations. Dent Mater. 2013;29(11):1158-65.

Bouschlicher MR, Rueggeberg FA, Wilson BM. Correlation of bottom-to-top surface microhardness and conversion ratios for a variety of resin composite compositions. Oper Dent. 2004;29(6):698-704. 
Boyer HE. Hardness testing. USA: ASM international; 1987.

Braz R, Ribeiro AIAM, Dantas DCRE, Correira TC, Figueirôa AFA, Cavalcanti AL. Selfetch Adhesive Systems: Effect of Acid and Proteolytic Etching on Bond Strength. Pesq Bras Odontoped Clin Integr. 2011;11(1):41-6.

Breschi L, Perdigão J, Lopes MM, Gobbi P, Mazzotti G. Morphological study of resin-dentin bonding with TEM and in-lens FESEM. Am J Dent. 2003;16(4):267-74.

Breschi L, Mazzoni A, Ruggeri A, Cadenaro M, Di Lenarda R, De Stefano Dorigo E. Dental adhesion review: aging and stability of the bonded interface. Dent Mater. 2008;24(1):90-101.

Cadenaro M, Breschi L, Rueggeberg FA, Suchko M, Grodin E, Agee K, et al. Effects of residual ethanol on the rate and degree of conversion of five experimental resins. Dent Mater. 2009;25(5):621-8.

Carvalho RM. Sistemas adesivos: fundamentos para aplicação clínica. Biodonto. 2004;2(1).

Carrilho MR, Carvalho RM, Tay FR, Yiu C, Pashley DH. Durability of resin-dentin bonds related to water and oil storage. Am J Dent. 2005;18(6):315-9.

Casas-Apayco LC, Dreibi VM, Hipólito AC, Graeff MS, Rios D, Magalhães AC, et al. Erosive cola-based drinks affect the bonding to enamel surface: an in vitro study. J Appl Oral Sci. 2014 Jun 10. [Epub ahead of print]

Chandra PV, Harikumar V, Ramkiran D, Krishna MJ, Gouda MV. Microleakage of class V resin composites using various self-etching adhesives: an in vitro study. J Contemp Dent Pract. 2013;14(1):51-5.

Chen H, Fu D, Yang H, Liu Y, Huang Y, Huang C. Optimization of direct currents to enhance dentine bonding of simplified one-step adhesive. Eur J Oral Sci. 2014;122(4):286-92.

Chersoni S, Suppa P, Grandini S, Goracci C, Monticelli F, Yiu C, et al. In vivo and in vitro permeability of one-step self-etch adhesives. J Dent Res. 2004;83(6):459-64.

Chung KH, Greener EH. Correlation between degree of conversion, filler concentration and mechanical properties of posterior composite resins. J Oral Rehab. 1990;17(5):487-94.

da Silva BM, França FM, Flório FM, Basting RT. In situ anticariogenic effect of adhesive systems containing fluoride and MDPB.Am J Dent. 2010;23(2):75-80. 
da Silva EM, Poskus LT, Guimarães JG. Influence of light-polymerization modes on the degree of conversion and mechanical properties of resin composites: a comparative analysis between a hybrid and a nanofilled composite. Oper Dent. 2008;33(3):287-93.

D'Alpino PH, Pereira JC, Svizero NR, Rueggeberg FA, Pashley DH. Factors affecting use of fluorescent agents in identification of resin-based polymers. J Adhes Dent. 2006;8(5):28592.a

D’Alpino PH, Pereira JC, Svizero NR, Rueggeberg FA, Pashley DH. Use of fluorescent compounds in assessing bonded resin-based restorations: a literature review. J Dent. 2006;34(9):623-34.b

De Munck J, Mine A, Poitevin A, Van Ende A, Cardoso MV, Van Landuyt KL, et al. Metaanalytical review of parameters involved in dentin bonding. J Dent Res. 2012;91(4):351-7.

De Munck J, Van Landuyt K, Peumans M, Poitevin A, Lambrechts P, Braem M, et al. A critical review of the durability of adhesion to tooth tissue: methods and results. J Dent Res. 2005;84(2):118-32.

Denk W, Strickler JH, Webb WW. Two-photon laser scanning fluorescence microscopy. Science. 1990;248(4951):73-6.

Diaspro A, Robello M. Two-photon excitation of fluorescence for three- dimensional optical imaging of biological structures. J Photochem Photobiol. 2000;55(1):1-8.

Dickens SH1, Cho BH. Interpretation of bond failure through conversion and residual solvent measurements and Weibull analyses of flexural and microtensile bond strengths of bonding agents. Dent Mater. 2005;21(4):354-64.

Ding PG, Wolff D, Pioch T, Staehle HJ, Dannewitz B. Relationship between microtensile bond strength and nanoleakage at the composite-dentin interface. Dent Mater.

2009;25(1):135-41.

Ellakuria J1, Triana R, Mínguez N, Soler I, Ibaseta G, Maza J, et al. Effect of one-year water storage on the surface microhardness of resin-modified versus conventional glass-ionomer cements. Dent Mater. 2003;19(4):286-90.

Elliott JE, Lovell LG, Bowman CN. Primary cyclization in the polymerization of Bis-GMA and TEGDMA: a modeling approch to understanding to cure of dental resin. Dent Mat. 2001;17(3):221-9. 
Fabre HS, Fabre S, Cefaly DF, de Oliveira Carrilho MR, Garcia FC, Wang L. Water sorption and solubility of dentin bonding agents light-cured with different light sources. J Dent. 2007;35(3):253-8.

Faria-e-Silva AL, Lima AF, Moraes RR, Piva E, Martins LR. Degree of conversion of etchand-rinse and self-etch adhesives light-cured using QTH or LED. Oper Dent. 2010;35(6):64954.

Ferracane JL. Correlation between hardness and degree of conversion during the setting reaction of unfilled dental restorative resins. Dent Mat. 1985;1(1):11-4.

Foxton, RM, Melo L, Stone DG, Pilecki P, Sherriff M, Watson TF. Long-term durability of one-step adhesive-composite systems to enamel and dentin. Oper Dent. 2008;33(6):651-7.

Francisconi LF, Graeff MS, Martins L de M, Franco EB, Mondelli RF, Francisconi PA, et al. The effects of occlusal loading on the margins of cervical restorations. J Am Dent Assoc. 2009;140(10):1275-82.

Fukegawa D, Hayakawa S, Yoshida Y, Suzuki K, Osaka A, Van Meerbeek B. Chemical interaction of phosphoric acid ester with hydroxyapatite. J Dent Res. 2006;85(10):941-4.

Garcia FC, Almeida JC, Osorio R, Carvalho RM, Toledano M. Influence of drying time and temperature on bond strength of contemporary adhesives to dentine. J Dent. 2009;37(4):31520.

Garcia F, D'Alpino P, Terada R, Carvalho R. Testes mecânicos para avaliação laboratorial da união resina/dentina. Rev Fac Odontol Bauru. 2002; 10(3):118- 27.

Garcia FC, Wang L, Pereira LC, de Andrade e Silva SM, Júnior LM, Carrilho MR. Influences of surface and solvent on retention of HEMA/mixture components after evaporation. J Dent. 2010;38(1):44-9.

Gordan VV, Vargas MA, Cobb DS, Denehy GE. Evaluation of adhesive systems using acidic primers. Am J Dent. 1997;10(5):219-23.

Griffiths BM, Watson TF. Resin-dentin interface of Scotchbond Multi- Purpose dentin adhesive. Am J Dent. 1995;8(4): 212-6.

Griffiths BM, Watson TF, Sherriff M. The influence of dentine bonding systems and their handling characteristics on the morphology and micropermeability of the dentine adhesive interface. J Dent. 1999;27(1):63-71. 
Gwinnett AJ. Moist versus dry dentin: its effect on shear bond strength. Am J Dent. 1992;5(3):127-9.

Hamouda IM, Al-Khodary AM, El Shami FM. Degree of conversion and antimicrobial activity of etch-and-rinse versus self-etching adhesives. J Adhes Dent. 2010 Feb;12(1):33-8.

Hansen EK, Asmussen E. Correlation between depth of cure and surface hardness of a lightactivated resin. Scand J Den Res. 1993;101(1):62-4.

Hashimoto M, Ohno H, Sano H, Kaga M, Oguchi H. In vitro degradation of resin-dentin bonds analyzed by microtensile bond test, scanning and transmission electron microscopy Biomaterials. 2003;24(21):3795-803.

Hotta M, Hirukawa H. Abrasion resistance of restorative glass-ionomer cements with a lightcured surfasse coating. Oper Dent. 1994;19(2);42-6.

Jacobsen T, Söderholm K-J. Some effects of water on dentine bonding. Dental Mater., 1995;11(2):132-6.

Kanca J. Effect of resin primer solvent and surface wetness on resin composite bond strength to dentine. Am J Dentistry, 1992;5(4):213-21.

Li J, von Beetzen M, Sundstrom F. Strength and setting behavior of resin-modified glass ionomer cements. Acta Odontl Scand. 1995;53(5):311-7.

Loguercio A, Luque-Martinez I, Muñoz M, Szesz A, Cuadros-Sánchez J, Reis A. A Comprehensive Laboratory Screening of Three-Step Etch-and-Rinse Adhesives. Oper Dent. 2014;39(6):652-62.

Luque-Martinez IV, Perdigão J, Muñoz MA, Sezinando A, Reis A, Loguercio AD. Effects of solvent evaporation time on immediate adhesive properties of universal adhesives to dentin. Dent Mater. 2014;30(10):1126-35.

Maciel KT, Carvalho RM, Ringle RD, Preston CD, Russell CM, Pashley DH. The effects of acetone, ethanol, HEMA, and air on the stiffness of human decalcified dentin matrix. J Dent Res. 1996;75(11):1851-8.

Martins GC, Meier MM, Loguercio AD, Reis A, Gomes JC, Gomes OM. Effects of adding barium-borosilicate glass to a simplified etch-and-rinse adhesive on radiopacity and selected properties. J Adhes Dent. 2014;16(2):107-14. 
Mena-Serrano A, Costa TR, Patzlaff RT, Loguercio AD, Reis A. Effect of Sonic Application Mode on the Resin-Dentin Bond Strength and Dentin Permeability of Self-etching Systems. J Adhes Dent. 2014 Sep 25. [Epub ahead of print]

Mendez JC, Pabon GE, Hilgenberg SP, Garcia EJ, Arana-Correa B. Effect of water storage on microtensile bond strength of a two-step self-etch adhesive and a two-step etch-and-rinse adhesive. Acta Odontol Latinoam. 2012;25(2):176-80.

Mertz-Fairhurst EJ, Curtis JW, Ergle JW, Rueggeberg FA, Adair SM. Ultraconservative and cariostatic sealed restorations: Results at year 10. J Am Dent Assoc. 1998;129(1):55-66.

Miyasaki M, Oshida Y, Moore BK, Onose H. Effect of light exposure on fracture toughness and flexural strength of light-cured composites. Dent Mater. 1996;12(6):328-32.

Mobarak EH, El-Deeb HA, Yousry MM. Influence of different intrapulpal pressure simulation liquids on the microtensile bond strength of adhesive systems to dentin. J Adhes Dent. 2013;15(6):519-26.

Nakabayashi, N. Bonding of restorative materials to dentine: the present status in Japan. Int Dent J. 1985;35(2):145-54.

Nakabayashi N, Kojima K, Masuhara E. The promotion of adhesion by the infiltration of monomers into tooth substrates. J Biomed Mater Res. 1982;16(3):265-73.

Pashley EL, Agee KA, Pashley DH, Tay FR. Effects of one versus two applications of an unfilled, all-in-one adhesive on dentine bonding. J Dent. 2002;30(2-3):83-90.

Pashley DH, Sano H, Ciucchi B, Yoshiyama M, Carvalho RM. Adhesion testing of dentin bonding agents: a review. Dent Mater. 1995;11(2):117-25.

Pashley DH, Tay FR, Imazato S. How to increase the durability of resin-dentin bonds. Compend Contin Educ Dent. 2011;32(7):60-4.

Pashley EL, Zhang Y, Lockwood PE, Rueggeberg FA, Pashley DH. Effects of HEMA on water evaporation from water-HEMA mixtures. Dent Mater. 1998;14(1):6-10.

Perdigão J. Dentin bonding-variables related to the clinical situation and the substrate treatment. Dent Mater. 2010;26(2):24-37 
Peumans M, Kanumilli P, De Munck J, Van Landuyt K, Lambrechts P, Van Meerbeek B. Clinical effectiveness of contemporary adhesives: a systematic review of current clinical trials. Dent Mater. 2005;21(9):864-81.

Pioch T, Stotz S, Staehle HJ, Duschner H. Applications of confocal laser scanning microscopy to dental bonding. Adv Dent Res. 1997;11(4):453-61.

Reis A, de Carvalho Cardoso P, Vieira LC, Baratieri LN, Grande RH, Loguercio AD. Effect of prolonged application times on the durability of resin-dentin bonds. Dent Mater. 2008;24(5):639-44.

Reis AF, Giannini M, Pereira PN. Long-term TEM analysis of the nanoleakage patterns in resin-dentin interfaces produced by different bonding strategies. Dent Mater.

2007;23(9):1164-72.

Rode KM, Kawano Y, Turbino ML. Evaluation of curing light distance on resin composite microhardness and polymerization. Oper Dent. 2007;32(6):571-8.

Rueggerberg FA, Craig RG. Correlation of parameters used to estimate monomer conversion in a ligjt-cured composite. J Dent Res. 1988;67(6):932-7.

Salvio LA, Hipólito VD, Martins AL, de Goes MF. Hybridization quality and bond strength of adhesive systems according to interaction with dentin. Eur J Dent. 2013;7(3):315-26.

Sampaio PC, Almeida Junior AA, Francisconi LF, Casas-Apayco LC, Pereira JC, Wang L, et al. Effect of Conventional and Resin-modified Glass Ionomer liner on Adhesive Interface Dentin/Resin, after Thermocycling. Oper Dent. 2011;36(4):403-12.

Sanares AME, Itthagarun A, King NM, Tay FR, Pashley DH. Adverse surface interactions between one-bottle light-cured adhesives and chemical-cured composites. Dent Mater. 2001;17(6): 542-55.

Sano H, Shono T, Takatsu T, Hosoda H. Microporous dentin zone beneath resin-impregnated layer. Oper Dent. 1994;19:59-64.

Sano H, Shono T, Sonoda H, Takatsu T, Ciucchi B, Carvalho R, et al. Relationship between surfasse área for adhesion and tensile bond strength evaluation of a microtensile bond test. Dent Mater. 1994;10(4):236-40.

Sano H, Yoshikawa T, Pereira PN, Kanemura N, Morigami M, Tagami J, et al.Long-term durability of dentin bonds made with a self-etching primer, in vivo. J Dent Res. 1999;78(4):906-11. 
Sauro S, Pashley DH, Mannocci F, Tay FR, Pilecki P, Sherriff M, et al Micropermeability of current self-etching and etch-and-rinse adhesives bonded to deep dentine: a comparison study using a double-staining/confocal microscopy technique. Eur J Oral Sci. 2008;116(2):184-93.

Scherrer SS, Cesar PF, Swain MV. Direct comparison of the bond strength results of the different test methods: a critical literature review. Dent Mater. 2010;26(2):78-93.

Schreiner RF, Chappell RP, Glaros AG, Eick JD. Microtensile testing of dentin adhesives. Dent Mater. 1998;14(3):194-201.

Schupbach P, Krejci I, Lutz F. Dentin bonding: effect of tubule orientation on hybrid-layer formation. Eur J Oral Sci. 1997;105(4):344-52.

Sideridou I, Tserki V, Papanastasiou G. Study od water sorption, solubility and modulus os elasticity of light-cured dimethacrylate-based dental resins. Biomaterials 2003;24(4):655-65.

Silva SM, Malacarne-Zanon J, Carvalho RM, Alves MC, De Goes MF, Anido-Anido A, et al. Effects of potassium oxalate on knoop hardness of etch-and-rinse adhesives. Oper Dent. 2012;37(4):356-62.

Souza SA. Ensaios mecânicos de materiais metálicos. Fundamentos teóricos e práticos, 5 th ed. São Paulo: Edgard Blücher ;1982.

Spencer P, Ye Q, Park J, Topp EM, Misra A, Marangos O, et al. Adhesive/Dentin Interface: The Weak Link in the Composite Restoration. Ann Biom Eng. 2010;38(6):1989-2003.

Sudsangiam S, Van Noort R. Do dentin bond strength tests serve a useful purpose? J Adhes Dent. 1999;1(1):57-67.

Swift JR EJ, Pawlus MA, Vargas MA, Fortin D. Depth of cure of resin-modified glass ionomers. Dent Mater. 1995;11(3):196-200.

Tay FR, Pashley DH. Aggressiveness of contemporary self-etching systems. I: Depth of penetration beyond dentin smear layers. Dent Mater. 2001 Jul;17(4):296-308.

Tay FR, Pashley DH, Yoshiyama M. Two modes of nanoleakage expression in single-step adhesives. J Dent Res. 2002;81(7):472-6.

Tay FR, Sano H, Carvalho R, Pashley EL, Pashley DH. An ultrastructural study of the influence of acidity of self-etching primers and smear layer thickness on bonding to intact dentin. J Adhes Dent. 2000;2(2):83-98. 
Toledano M, Osorio R, Osorio E, Aguilera FS, Yamauti M, Pashley DH, et al. Durability of resin-dentin bonds: effects of direct/indirect exposure and storage media. Dent Mater. 2007;23(7):885-92.

Turbino ML, Belan LC, Soprano V, Rode KM, Lloret PR, Youssef MN. Argon ion laser curing depth effect on a composite resin. Lasers Med Sci. 2011;26(4):421-5.

Van Dijken JW. A prospective 8-year evaluation of a mild two-step self-etching adhesive and a heavily filled two-step etch-and-rinse system in non-carious cervical lesions. Dent Mater. 2010;26(9):940-6.

Van Landuyt KL, Snauwaert J, De Munck J, Peumans M, Yoshida Y, Poitevin A, et al. Systematic review of the chemical composition of contemporary dental adhesives. Biomaterials. 2007;28(26):3757-85.

Van Meerbeek, B, Dhem A, Goret-Nicaise M, Braem M, Lambreschts P, VanHerle G. Comparative SEM and TEM examination of the ultrastructure of the resin-dentin interdiffusion zone. J Dent Res. 1993;72(2):495-501.

Van Meerbeek B, De Munck J, Mattar D, Van Landuyt K, Lambrechts P. Microtensile bond strengths of an etch\&amp;rinse and self-etch adhesive to enamel and dentin as a function of surface treatment. Oper Dent. 2003;28(5):647-60.

Van Meerbeek B, Peumans M, Poitevin A, Mine A, Van Ende A, Neves A, et al. Relationship between bond-strength tests and clinical outcomes. Dent Mater. 2010;26(2):100-21.

Van Meerbeek B, Van Landuyt K, De Munck J, Hashimoto M, Peumans M, Lambrechts P, et al. Technique-sensitivity of contemporary adhesives. Dent Mater J. 2005 Mar;24(1):1-13.

Van Meerbeek B, Yoshihara K, Yoshida Y, Mine A, De Munck J, Van Landuyt KL. State of the art of self-etch adhesives. Dent Mater. 2011;27(1):17-28

Vargas MA, Cobb DS, Armstrong SR. Resin-dentin shear bond strength and interfacial ultrastructure with and without a hybrid layer. Oper Dent. 1997;22(4):159-66.

Zheng P, Zaruba M, Attin T, Wiegand A. Effect of Different Matrix Metalloproteinase Inhibitors on Microtensile Bond Strength of an Etch-and-Rinse and a Self-etching Adhesive to Dentin. Oper Dent. 2014 May 9. [Epub ahead of print]

Walter R, Duarte WR, Pereira PN, Swift EJ Jr, Heymann HO, Arnold RR. Effect of resin adhesive systems on root caries formation in vitro. Quintessence Int. 2008;39(1):33-7. 
Watson TF. A confocal optical microscope study of the morphology of the tooth/restoration interface using Scotchbond 2 dentin adhesive. Journal of Dental Research 1989;68(6):112431 .

Watson TF. Applications of confocal scanning optical microscopy to dentistry. Br Dent J 1991;171(9):287-91.

Watson TF. Fact and artefact in confocal microscopy. Adv Dent Res 1997;11(4):433-41.

Watson TF. Boyde A. Tandem scanning reflected light microscopy: applications in clinical dental research. Scanning Microsc, 1987;1(4):1971-81.

Yap AU, Mudambi S, Chew CL, Neo JC. Mechanical properties of an improved visible lightcured resin-modified glass ionomer cement. Oper Dent. 2001;26(3):295-301.

Yearn JA. Factors affecting cure of visible light activated composites. Int Dent J.

1985;35(3):218-2.

Yli-Urpo H, Lassila LV, Narhi T, Vallittu PK. Compressive strength and surface characterization of glass-ionomer cements modified by particles of bioactive glass. Dent Mat. 2005;21(3):201-9.

Yoshihara K, Yoshida Y, Nagaoka N, Fukegawa D, Hayakawa S, Mine A, et al. Nanocontrolled molecular interaction at adhesive interfaces for hard tissue reconstruction. Acta Biomater. 2010;6(9):3573-82. 
ANEXOS 



\section{Anexo 1: Aprovação do Comitê de Ética em Pesquisa em Seres Humanos}

\section{FACULDADE DE ODONTOLOGIA DE BAURU- USP}

\section{PARECER CONSUESTANCLADO DO CEP}

\section{DADOS DO PROJETO DE PESOUISA}

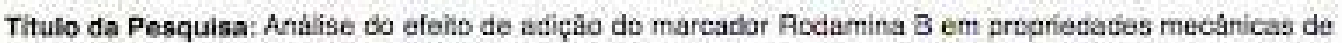
sistemas adeshos náp simpiticacos

Pesquisador: Camila Moreira Machado

Área Tembtica:

Versảo: 2

CAAE: 17406313.6 .0000 .5417

Institulçalo Proponente: Universidade de Sao Paulo

Patrocinador Principal: Financiamenlo Prêpeio.

\section{DADOS DO PARECEA}

Nümero do Parecer: 526.798

Data da Pelatoris: 1002/2014

\section{Apresenteçẫo do Projeto:}

$O$ arojeto de pesquisa "Analise to eleito de adição do marcador Aldemina B em propriedades mecânicas de sistemas adesivos năo simplificados' apresenta como pesquisadora tesponsável Camila Moreira Machado e integrantes ta equipe de pesquisa a Prola. Dra. Linda Wang a Odair Bim Jünor. Apresenta

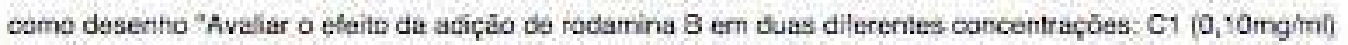
e C2 (mence concentrapāo que secá teterminada etn tstuto pitota) ern sistemas adesivos măo simplificadas considerados padrắa-bura".

\section{Objotivo da Pesquisa:}

0 objetivo deste estude in vitro $\theta$ avalar, por melo da resistencia de unias e da microdureza superticial, o eteito da adicao de duas concsntraçes de rodamina B nos sistemas adesivos nas simplíticados Adper Scotchbond Mult-Furpose o Cleartil SE Bond

Avaliaçăo dos Riscos e Beneticios:

Nầ apresenta fiscos au benelicios por se tratar de pesquise in vitro com dentes extraidos.

Comentários e Consideraços sobre n Pesquisa:

O projeto de pesquisa esta com metosologla e cbjettvos bem detahados a descritos. Apresenta hipotese $\theta$ justificativa adequada, ndo possui comprometimento etico e naco envolve riscos. Propoe dispensa do TCLE.

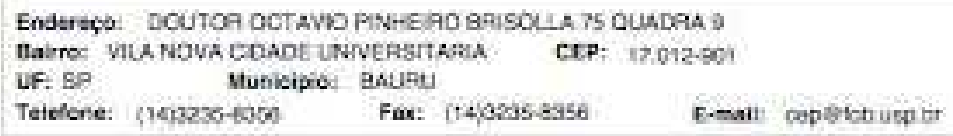




\section{FACULDADE DE ODONTOLOGIA DE BAURU- USP}

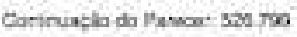

Considerą̧ons sobre os Tormos de apresentagho obeigatória:

Os documentos foram enwados e estibo corretos: Projeto ge pesquisa folha de rosto, curriculo lates da pesquisadora $\theta$ cos assistentes, orgamento, declaraçso para susponder, autorizaça do chete de departamento, autorizaça para publcaçăo, termo de doaça. Propoe dispensa do TCLE. Coma o projeso retomou as CEP houve a correta ceformulaça do cronograma.

\section{Recomendaçōes:}

Nenhums

Conclusoes ou Pendéncias e Lista de Inndequaçbes:

Os autores agresentaram o projete de forma adequade $\theta \mathrm{com}$ a documentapáo completa. Num primeiro momento (novembro de 2013) o projeta toi considerado com pendéncia em virtude dos autores terem

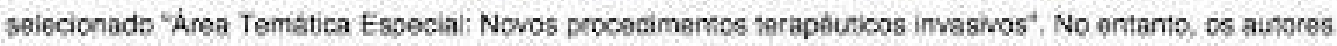

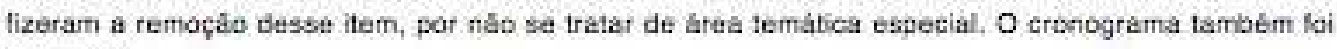
atualizado.

Dessa maneira os ausores fzeram as aiteraçbes neoessárias e recomendamos a eprovaçăo do mesmo.

\section{Situaça do Parecer:}

Aprovado

Necessita Apreciaçào da CONEP:

Năอ

Consideraços Finais a critério do CEP:

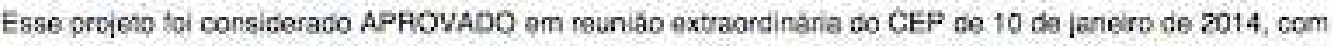
jase nas normas ética da Resoluça CNS $466 / 12$. Ao termino da pesquisa o CEF-FOB/USP exige a apresentaça de relatbrio tinal. Cs relatories pacciais deveráo estar de acorco com o cronograma elou

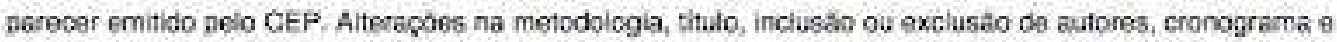
quaisquer outras mudanças que sejam significabivas deverao ser previamente camunicedas a este CEP sob risco de nâo aprovaçä́ do milatbno tinal. Quando da apresentaço deste, deveralo ser incluidos todos os TCLEs elou tarmos de dosçĭo assinados a rubcicados.

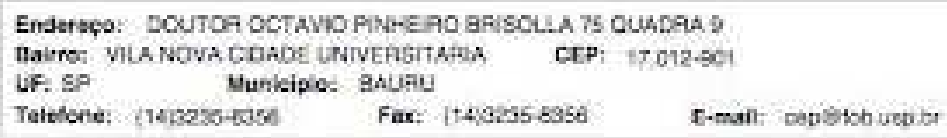




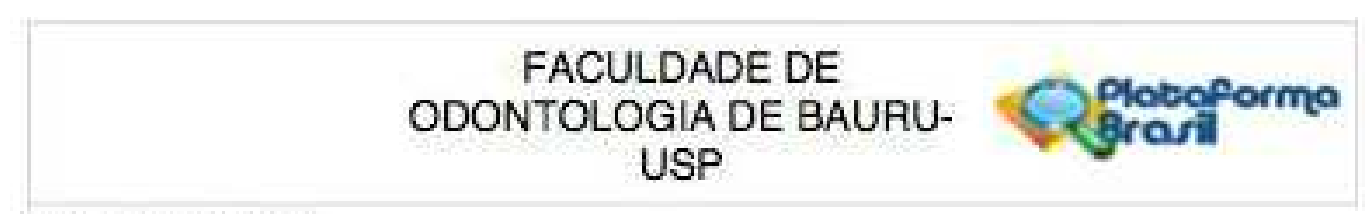

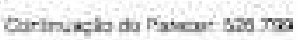

BAURU, 11 te Favestiro de 2014

\section{Assinador por:}

tzabel Rogina Fischer Rubira Bullen

(Coordenador) 
Anexo 2: Termo de doação de dentes humanos por cirurgiões-dentistas

\section{TERMO DE DOAÇÃO DE DENTES HUMANOS POR CIRURGIÕES-DENTISTAS}

Eu, Henrique Taniguchi, Cirurgião-dentista, inscrito no CRO sob o número 8865 , com consultório situado à Avenida Multirão, 2361, no bairro Setor Marista, na cidade de Goiânia, UF GO, CEP 74150-340, telefone 62-3941-7282, dôo 90 dentes para Profa. Dra. Linda Wang para a realização da pesquisa na Faculdade de Odontologia de Bauru, "Análise do efeito de adição do marcador Rodamina B em propriedades mecânicas de sistemas adesivos não simplificados" de autoria de Camila Moreira Machado, Odair Bim Junior e Linda Wang. Declaro que estes dentes foram extraídos por indicação terapêutica, cujos históricos fazem parte dos prontuários dos pacientes de quem se originam, arquivados sob minha responsabilidade. Estou ciente de que o material recolhido será utilizado pelos pesquisadores desta Faculdade unicamente para a realização da presente pesquisa.

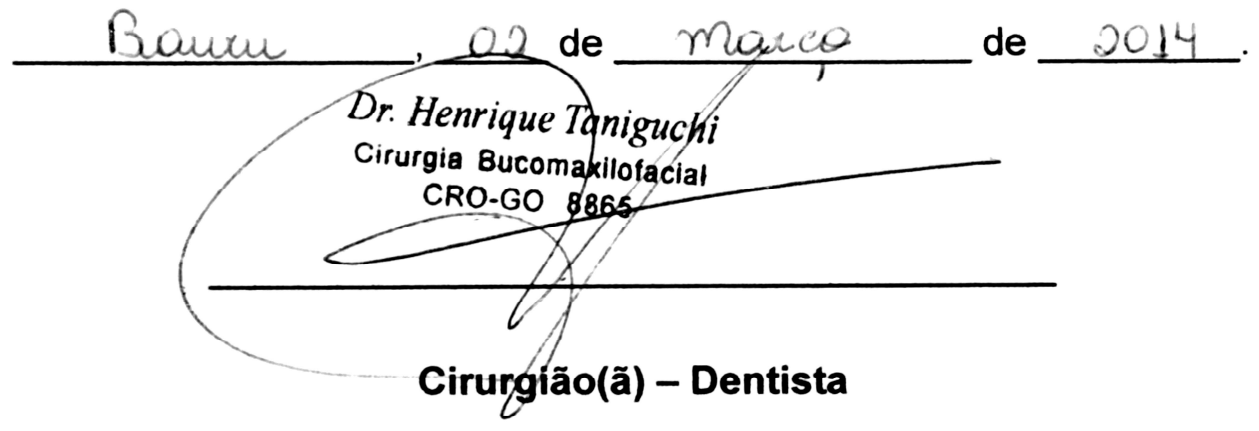


Anexo 3: Termo de doação de dentes humanos por cirurgiões-dentistas

\section{TERMO DE DOAÇÃO DE DENTES HUMANOS POR CIRURGIÕES-DENTISTAS}

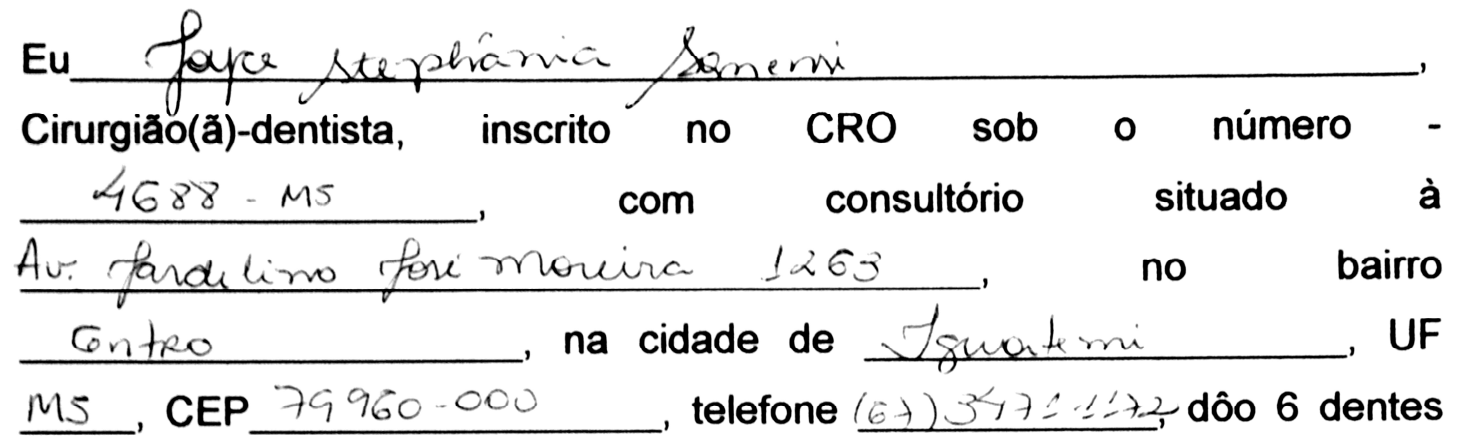

para Profa. Dra. Linda Wang para a realização da pesquisa na Faculdade de Odontologia de Bauru, "Análise do efeito de adição do marcador Rodamina B em propriedades mecânicas de sistemas adesivos não simplificados", de autoria de Camila Moreira Machado, Odair Bim Júnior - Linda Wang. Declaro que estes dentes foram extraídos por indicação terapêutica, cujos históricos fazem parte dos prontuários dos pacientes de quem se originam, arquivados sob minha responsabilidade. Estou ciente de que o material recolhido será utilizado pelos pesquisadores desta Faculdade unicamente para a realização da presente pesquisa.

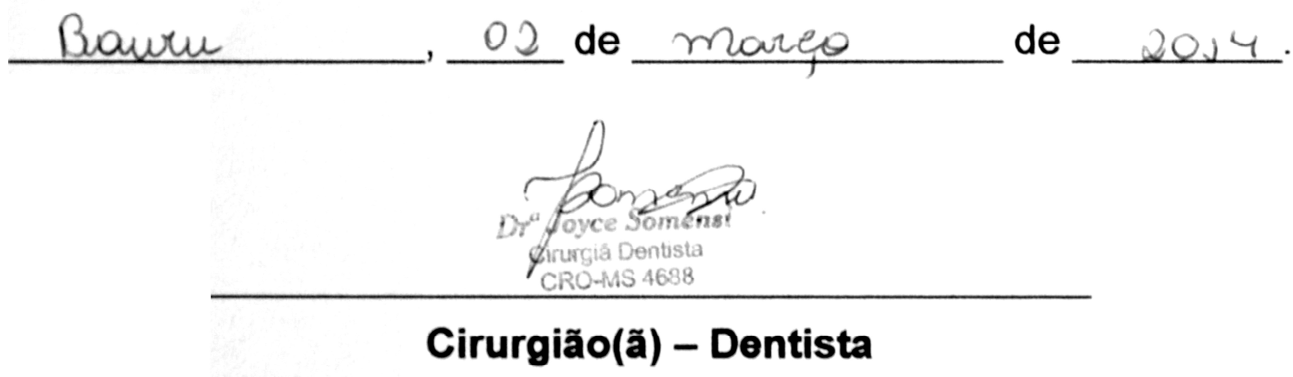

